\title{
Methodology Using MELCOR Code to Model Proposed Hazard Scenario
}

Gavin C. Hawkley

July 2010

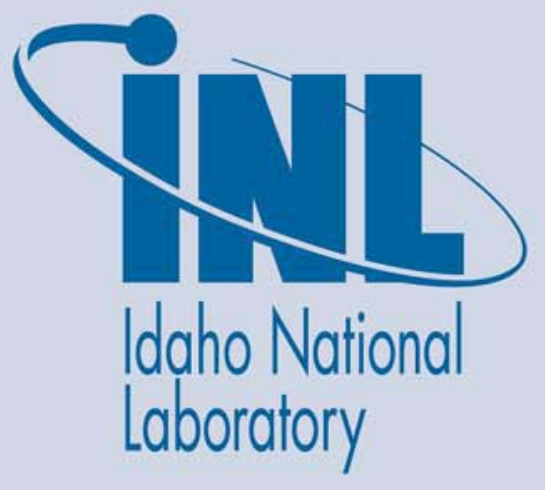

The INL is a U.S. Department of Energy National Laboratory operated by Battelle Energy Alliance 
INL/EXT-10-19581

\title{
Methodology Using MELCOR Code to Model Proposed Hazard Scenario
}

\author{
Gavin C. Hawkley
}

July 2010

\section{Idaho National Laboratory \\ Emergency Management Idaho Falls, Idaho 83415}

http://www.inl.gov

\author{
Prepared for the \\ U.S. Department of Energy \\ Office of Nuclear Energy \\ Under DOE Idaho Operations Office \\ Contract DE-AC07-05ID14517
}




\section{DISCLAIMER}

This information was prepared as an account of work sponsored by an agency of the U.S. Government. Neither the U.S. Government nor any agency thereof, nor any of their employees, makes any warranty, expressed or implied, or assumes any legal liability or responsibility for the accuracy, completeness, or usefulness, of any information, apparatus, product, or process disclosed, or represents that its use would not infringe privately owned rights. References herein to any specific commercial product, process, or service by trade name, trade mark, manufacturer, or otherwise, does not necessarily constitute or imply its endorsement, recommendation, or favoring by the U.S. Government or any agency thereof. The views and opinions of authors expressed herein do not necessarily state or reflect those of the U.S. Government or any agency thereof. 
This page intentionally left blank. 
Emergency Management

\title{
Methodology Using MELCOR Code to Model Proposed Hazard Scenario
}

\author{
INL/EXT-10-19581 \\ Revision 0
}

July 2010

Approved by:

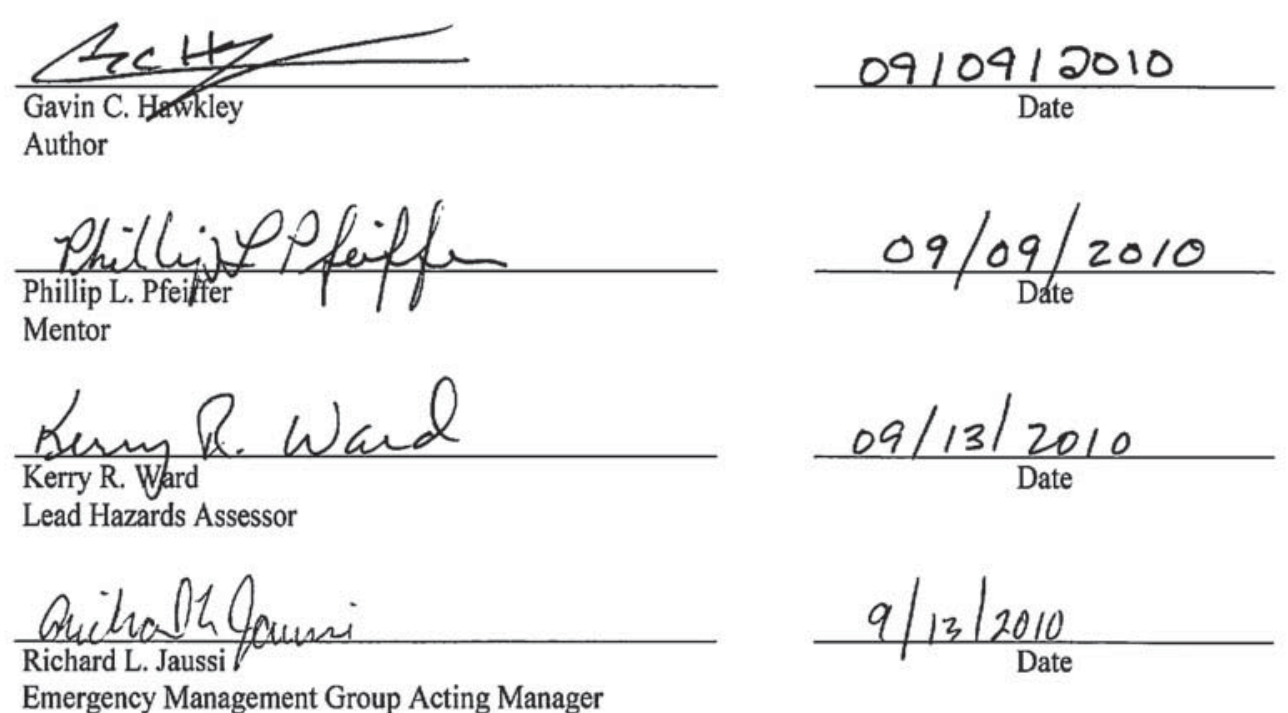


This page intentionally left blank 


\begin{abstract}
This study demonstrates a methodology for using the MELCOR code to model a proposed hazard scenario within a building containing radioactive powder, and the subsequent evaluation of a leak path factor (LPF) (or the amount of respirable material that escapes a facility into the outside environment) implicit in the scenario. This LPF evaluation analyzes the basis and applicability of an assumed standard multiplication of $0.5 \times 0.5$ (in which 0.5 represents the amount of material assumed to leave one area and enter another) for calculating an LPF value. The outside release depends on the ventilation/filtration system, both filtered and unfiltered, and other pathways from the building, such as doorways (both open and closed). This study presents how multiple LPFs from the interior building can be evaluated in a combinatory process in which a total LPF is calculated, thus addressing the assumed multiplication, and allowing for the designation and assessment of a respirable source term for later consequence analysis, in which the propagation of material released into the environmental atmosphere can be modeled and the dose received by a receptor placed downwind can be estimated and the distance adjusted to maintain such exposures as low as reasonably achievable. Also, this study briefly addresses particle characteristics that affect atmospheric particle dispersion and compares this dispersion with LPF methodology.
\end{abstract}


This page intentionally left blank. 


\section{CONTENTS}

ABSTRACT vii

ACRONYMS xi

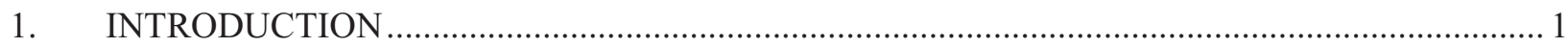

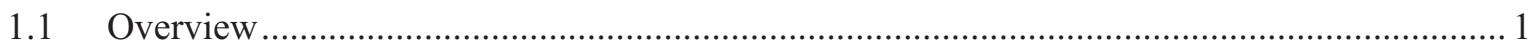

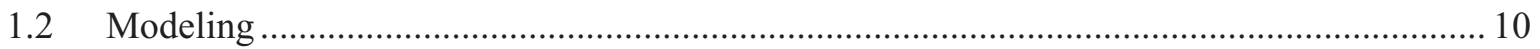

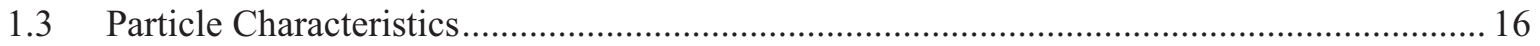

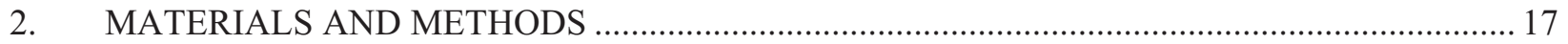

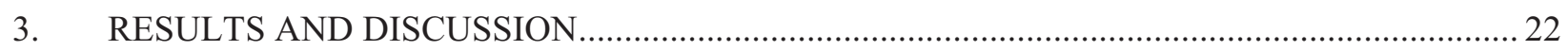

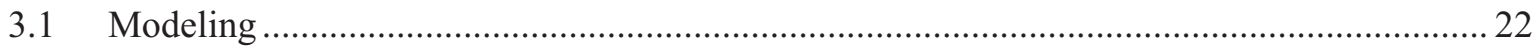

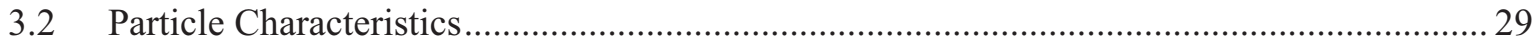

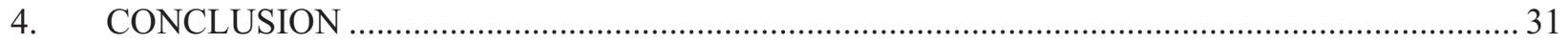

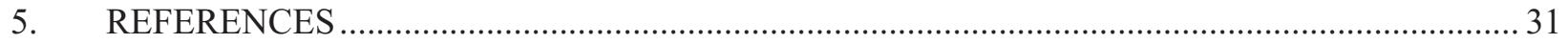

\section{FIGURES}

1. Conceptual flow diagram for source term development and human health effects .........................2

2. Settling velocity of test particle measured and compared to reference particle, unit density

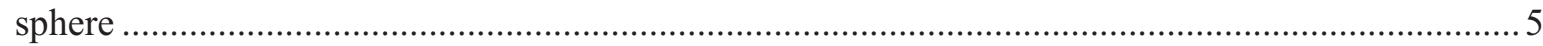

3. Regional deposition of particulate matter in the lung .............................................................. 5

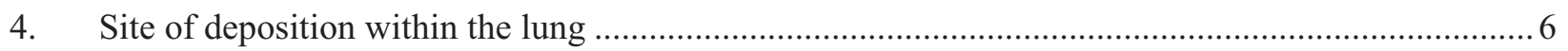

5. Percent penetrating the lung by aerodynamic equivalent diameter .............................................. 6

6. Inertial impaction — mechanism of particle deposition within the lung ........................................ 7

7. Interception — mechanism of particle deposition within the lung ............................................... 8

8. Sedimentation (gravitational settling) - mechanism of particle deposition within the lung ............. 8

9. Diffusion — mechanism of particle deposition within the lung .................................................... 9

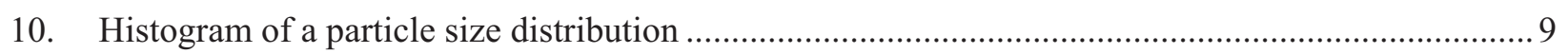

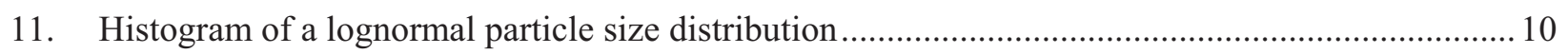

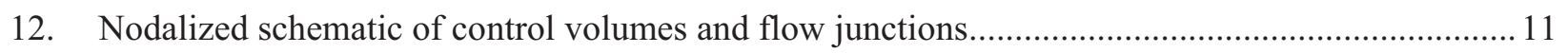

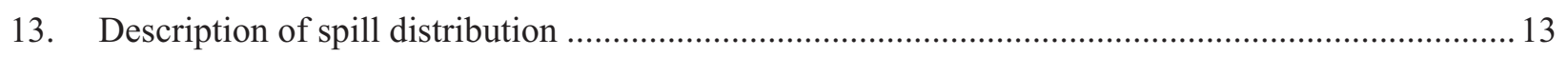

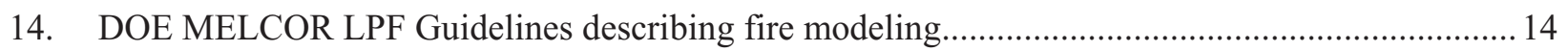

15. DOE MELCOR LPF Guidelines describing fire modeling (cont.) ............................................... 15

16. Three-dimensional model of the facility of interest ................................................................. 18

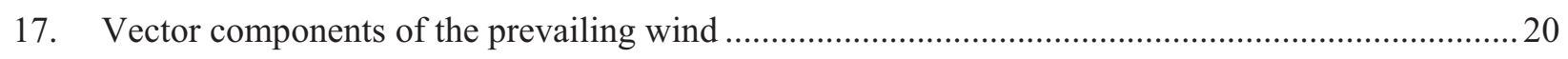

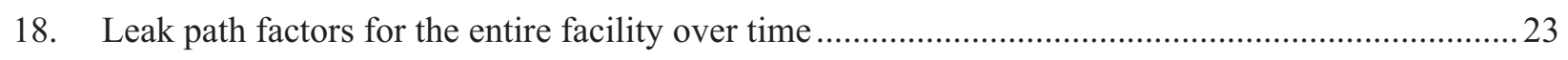

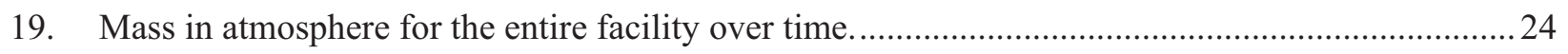


20. Leak path factor from the simplified truck lock model for the respirable range and all particle sizes at $4.47 \mathrm{~m} / \mathrm{s}$

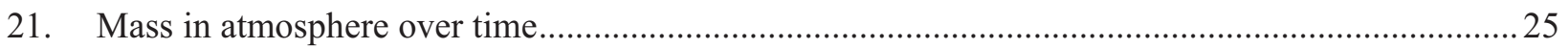

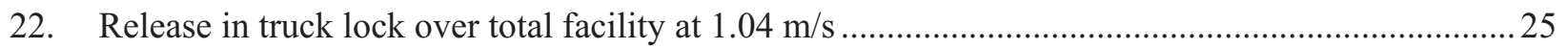

23. Release in truck lock to the north environmental volume at $1.04 \mathrm{~m} / \mathrm{s}$........................................26

24. Amount in atmosphere for truck lock release over the main model at $1.04 \mathrm{~m} / \mathrm{s}$.........................26

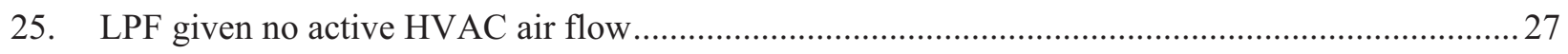

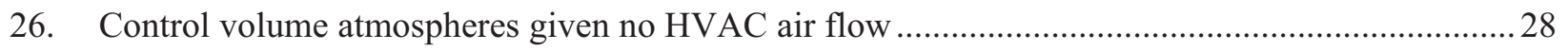

\section{TABLES}

1. Aerodynamic resistance to deposition in the transport layer ...................................................... 17

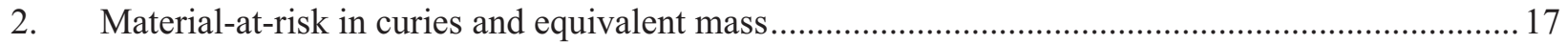

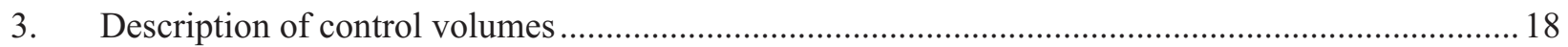

4. Flow paths (from center elevation to center elevation) and the limiting flow path areas ................ 19

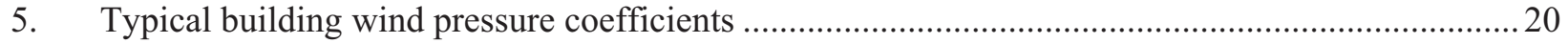

6. Delta $\mathrm{P}$ and absolute pressure for the environmental volumes - normal atmospheric

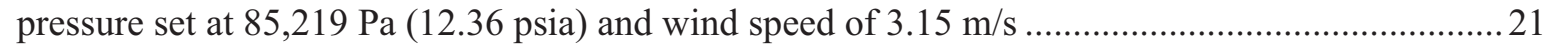

7. Delta $\mathrm{P}$ and absolute pressure for the environmental volumes - normal atmospheric

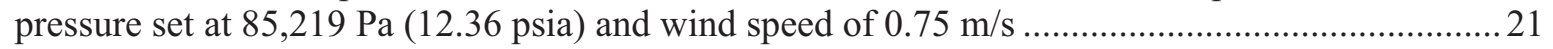

8. Density, aerodynamic equivalent diameter, and geometric diameter of the specific radionuclide released. 


\section{ACRONYMS}

$\begin{array}{ll}\text { AED } & \text { aerodynamic equivalent diameter } \\ \text { ARF } & \text { airborne release fraction } \\ \text { DOE } & \text { Department of Energy } \\ \text { DR } & \text { damage ratio } \\ \text { HFEF } & \text { Hot Fuel Examination Facility } \\ \text { HVAC } & \text { heating, ventilation, and air conditioning } \\ \text { LPF } & \text { leak path factor } \\ \text { MAR } & \text { material-at-risk } \\ \text { PDF } & \text { probability density function } \\ \text { RF } & \text { respirable fraction } \\ \text { ST } & \text { source term }\end{array}$


This page intentionally left blank. 


\section{Methodology Using MELCOR Code to Model Proposed Hazard Scenario 1. INTRODUCTION}

\subsection{Overview}

The process of screening hazardous material is performed for analysis of potential airborne hazards that potentially threaten workers, the public, and/or the environment. The process identifies facilities where hazardous material, if accidentally released, could propagate through the facility and disperse to the environment (GDE-437 $)$. DOE O 151.1C ${ }^{2}$ states: "Operational Emergencies are major unplanned or abnormal events or conditions that: involve or affect DOE/NNSA facilities and activities by causing or having the potential to cause serious health and safety or environmental impacts; require resources from outside the immediate/affected area or local event scene to supplement the initial response; and, require time-urgent notifications to initiate response activities at locations beyond the event scene."

The initiating event of an accidental release may be due to one of the following three broad categories:

1. External initiator; event originates outside the facility and may compromise the facility's hazardous material confinement capabilities

2. Internal initiator; event originates inside a facility, possibly due to equipment and/or human failure, and may impact the ability of the facility to operate

3. Natural phenomena initiator, which includes a flood, tornado, or seismic event; event may cause facility failure or jeopardize facility containment.

Facility containment may include a preventative feature, such as a structure, system, or component that acts as a passive barrier between the hazardous material from an accident scenario and the environment. Passive barriers include, but are not limited to, piping; containers; gloveboxes; facility structure; containment systems and their respective components, such as pressure relief valves; and automated monitoring systems with built-in safeguards. (DOE/ID-10471 ${ }^{3}$ )

To combat the risk of a hazardous release, time-urgent responses must be implemented to effectively mitigate the implicit release conditions. ${ }^{1}$ A mitigative feature includes any structure, system, or component that decreases the consequential release of hazardous material during an accident scenario, such as air filtration systems. ${ }^{3}$

Release conditions or events and conditions that could influence the propagation of hazard scenarios or alter the nature and extent of the associated consequences should be identified elementary, and in compliance with 10 CFR 830, Subpart B. ${ }^{4} 10$ CFR 830, Subpart B, became effective January 10, 2001, and contains specific requirements for facility authorization basis documents, such as the unreviewed safety question process, a documented safety analysis, technical safety requirements, and a preliminary documented safety analysis. 10 CFR 830, Subpart B, also provides an implementation schedule for compliance.

Release conditions describe the functional condition of structures and relief systems with influence of the designated initiating event, such as release to the environment; rate of, magnitude of, and location of (elevated versus ground level). Also, release condition identification is the final step within the selection of hazard scenarios that are significant for analysis. These release condition scenarios consist of material-at-risk (MAR), possible initiating events, failure modes, and identified release conditions. Release scenarios are analyzed to further quantify the release to the environment by producing an estimate of the source term (ST), the quantities of radionuclides released. (DOE G 151.1-2 ${ }^{5}$ ) 
In 1962, the Atomic Energy Commission published some assumptions that should be made during a nuclear event, thus introducing, and making it possible to calculate a ST (Gesell 1997 ${ }^{6}$ ). The ST is defined as the product of five terms as shown in Equation No. 1.

$$
\text { Equation No. } 1 \quad \mathrm{ST}=\mathrm{MAR} \times \mathrm{DR} \times \mathrm{ARF} \times \mathrm{RF} \times \mathrm{LPF}
$$

Where:

$$
\begin{aligned}
& \mathrm{ST}=\text { source term } \\
& \mathrm{MAR}=\text { material-at-risk } \\
& \mathrm{DR}=\text { damage ratio } \\
& \mathrm{ARF}=\text { airborne release fraction } \\
& \mathrm{RF}=\text { respirable fraction } \\
& \mathrm{LPF}=\text { leak path factor. }
\end{aligned}
$$

Together, the MAR and DR terms represent the amount of radiological material that is exposed to an accident-generated initiating event. The ARF and RF product represents the fraction of this material, within the respirable size range $[10 \mu \mathrm{m}$ or less aerodynamic equivalent diameter (AED)], that is made airborne in response to the accident-generated initiating event. Thus, the product of the first four terms represents the amount of radioactive material, within the respirable size range, that is made airborne inside the building. The basis of the analysis and the main focus of this study is the LPF calculation, which signifies the fraction of respirable radioactive material that is made airborne, and leaves the building through the various release pathways, thus entering the outside environment (Polizzi et al. ${ }^{7}$ ). A simplification of these pathways is shown in Figure 1 (Mueller $1995^{8}$ ).

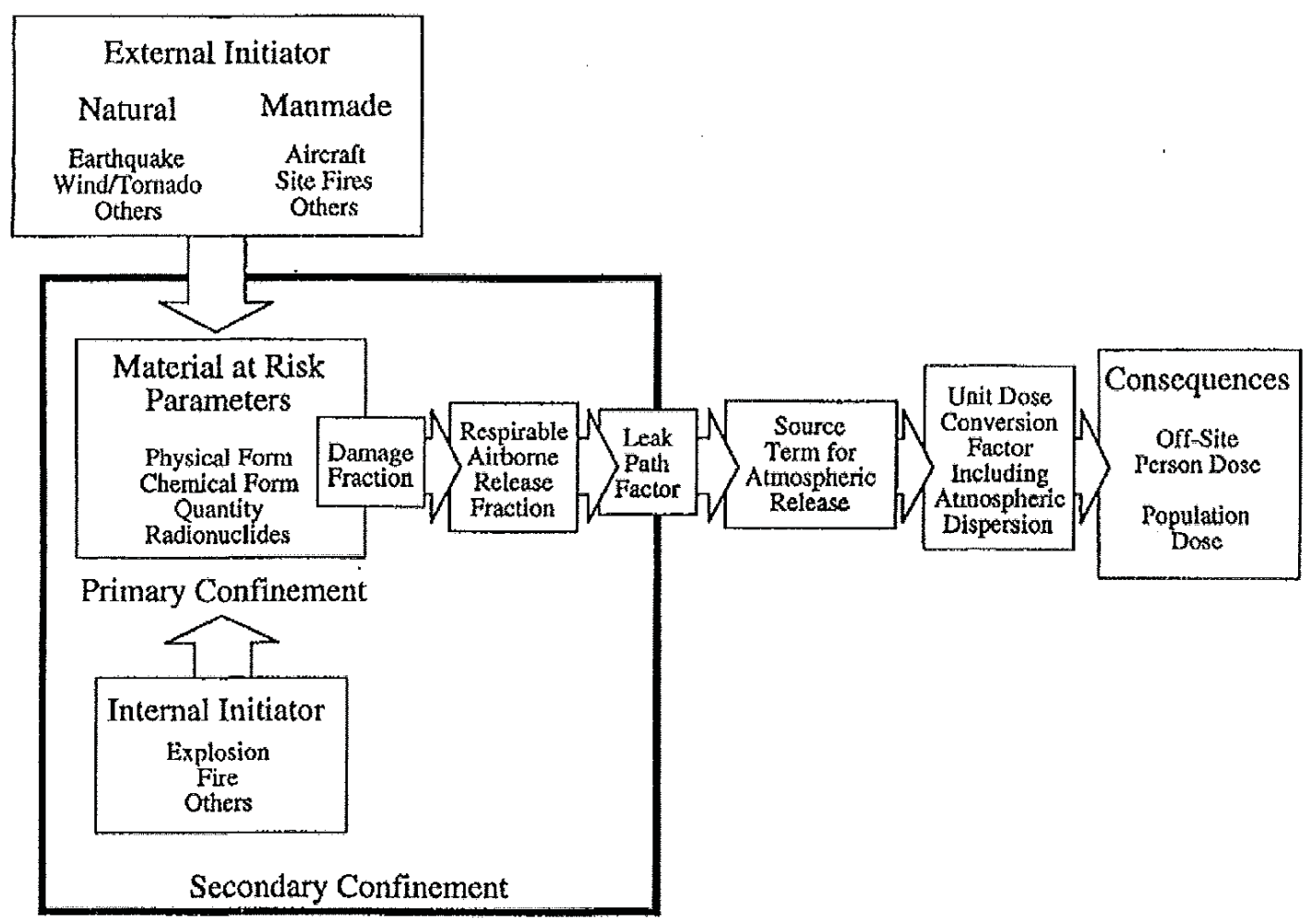

Figure 1. Conceptual flow diagram for source term development and human health effects. ${ }^{8}$ 
Accident analysis, specifically LPF calculations, is an integral part of the safety-based mitigation for both nuclear and non-nuclear facilities. Confirming that LPF calculations are adequately conservative is very important to the process (Siebe et al. $2007^{9}$ ). The value is conservative if the sum of its assumptions adequately exaggerate the consequences of the actual accident under analysis. ${ }^{3}$ A conservative LPF aids in the determination of an applicably conservative ST value and thus an accurately conservative consequence analysis.

According to ECAR-951, ${ }^{10}$ the LPF is the fraction of the radionuclides in the aerosol transported through some confinement deposition or filtration mechanism. LPFs may be calculated or standard values based on (1) established relationships between size of the particulate material, airborne transport mechanisms, and losses by deposition mechanisms; or (2) specified filtration efficiencies. ${ }^{10}$ Thus, the LPF can be manipulated to express the percentage of contaminants within the cell atmosphere that plates out on various surfaces before it can escape to the outside environment (DSA-003-HFEF ${ }^{11}$ ).

There can be multiple LPFs for some accident conditions. For example, the fraction released from a shipping or storage container to a cell or an enclosure; the fraction leaked from the cell or enclosure to an operating area around the cell or enclosure, and the fraction leaked from the operating room to the building atmosphere. Where multiple leak paths are involved, their cumulative effect may be conveyed as the product of all the leak paths. (ECAR- $475^{12}$ )

This study was performed to either add validity to an operating LPF assumption, or to disprove this assumption. The assumption is referred to as the $0.5 \times 0.5$ assumption and is based on the fractionation of the source by each enclosure within a facility of interest for which the ST moves through.

DSA-003-HFEF, Chapter 3, HFEF Hazards Assessment, Subsection 3.4.4.3.2, Seismic Event Causing a Cell Breach and Metal Oxidation, assigns an LPF value of 0.5 for each enclosure and states: “... it is assumed that $50 \%$ of the contaminants plate out in the main cell, $50 \%$ of that remaining plates out in the ducts and pipes, and $50 \%$ of what is left plates out in the building. So the fraction of the contaminants originally in the cell atmosphere following the accident that actually makes it to the outside is $(50 \% \times 50 \% \times 50 \%)=0.125 . "{ }^{\prime 10}$ Given the desired calculation of a respirable ST, the RF becomes a very important parameter implicit to the LPF. DOE-HDBK-3010-94 ${ }^{13}$ states:

"The RF is the fraction of airborne radionuclides as particles that can be transported through air and inhaled into the human respiratory system and is commonly assumed to include particles 10- $\mu \mathrm{m}$ Aerodynamic Equivalent Diameter (AED) and less. Other definitions of "respirable particles"....

The size of a particle is a function of the measurement technique used. If the method used is optical/electron microscopy or spectrometry, particle size is a projected diameter measured by the plane that intercepts the light/electron beam or reflection from light scattered by the particle. The size represents the two-dimensional area intercepting the beam and, as with all projections of three dimensions into two, can result in considerable distortion. Projected diameter approximates the Geometric Diameter $\left(\mathrm{D}_{\mathrm{g}}\right)$. $\mathrm{D}_{\mathrm{g}}$ is also approximated by sieving where the size measurement is termed geometric/....diameter. The measurement represents.... 
Liquid and air sedimentation techniques of inertial impaction by a cascade impactor measure the settling velocity of a particle and report size as an aerodynamic characteristic. Size is reported as an equivalent sphere with an equivalent settling velocity, or.... The Aerodynamic Diameter $\left(\mathrm{D}_{\mathrm{AED}}\right)$ specifically refers to an equivalent sphere with a density of $1 \mathrm{~g} / \mathrm{cm}^{3} . D_{\mathrm{AED}}$ is the parameter of interest for defining respirable particles....as it normalizes materials of different density. Other size units.... $D_{g}$ is related to $\mathrm{D}_{\mathrm{AED}}$ by the equation:

$$
\mathrm{D}_{\mathrm{AED}}=\left(\mathrm{D}_{\mathrm{g}}\left[\rho_{\mathrm{p}}\right]^{0.5}\left[\mathrm{C}_{\mathrm{c}, \mathrm{e}} / \mathrm{C}_{\mathrm{c}, \mathrm{a}}\right]^{0.5}\right) / \alpha
$$

where:

$\rho_{\mathrm{p}}=$ Particle density $\left(\mathrm{g} / \mathrm{cm}^{3}\right)$,

$\mathrm{C}_{\mathrm{c}, \mathrm{e}}=$ Cunningham slip factor corresponding to volume equivalent diameter,

$\mathrm{C}_{\mathrm{c}, \mathrm{a}}=$ Cunningham slip factor corresponding to the aerodynamic equivalent

diameter, and

$\alpha=$ Aerodynamic shape factor.

The Cunningham slip factor....

Although the principal emphasis in this document is directed toward the potential downwind hazard to the populations at some distance from the point of source term generation, airborne particles larger than $10-\mu \mathrm{m}$ AED released from the facility may constitute an onsite hazard (direct radiation) and may (if the larger particles are agglomerates that de-agglomerate with time or can be subdivided by local conditions) be subject to re-dispersal. If direct shine..."

The Cunningham slip factor accounts for the potential for particle collision with the mean free paths of air molecules. Beyond the sub-micron range, all particles collide with air molecules, thus the slip factor can be ignored. Also, the aerodynamic shape factor is typically unknown and is assumed to be 1 . Therefore, $\mathrm{D}_{\mathrm{AED}}$ can be estimated by multiplying $\mathrm{D}_{\mathrm{g}}$ by the square root of particle density. [Department of Energy (DOE) MELCOR LPF Guidelines Final Report ${ }^{14}$ ]

Furthermore, implicit in the AED of a particle are measurement of particle behavior in air, the function of particle diameter, density, shape, and surface characteristics. The AED is referenced to a spherical drop of water with identical settling velocity as shown in Figure 2, which effects air sampling characteristics (Johns Hopkins University School of Public Health ${ }^{15}$ ), and determines the site of deposition in the lung as shown in Figures 3 and 4 (Breysse ${ }^{16}$ ). 


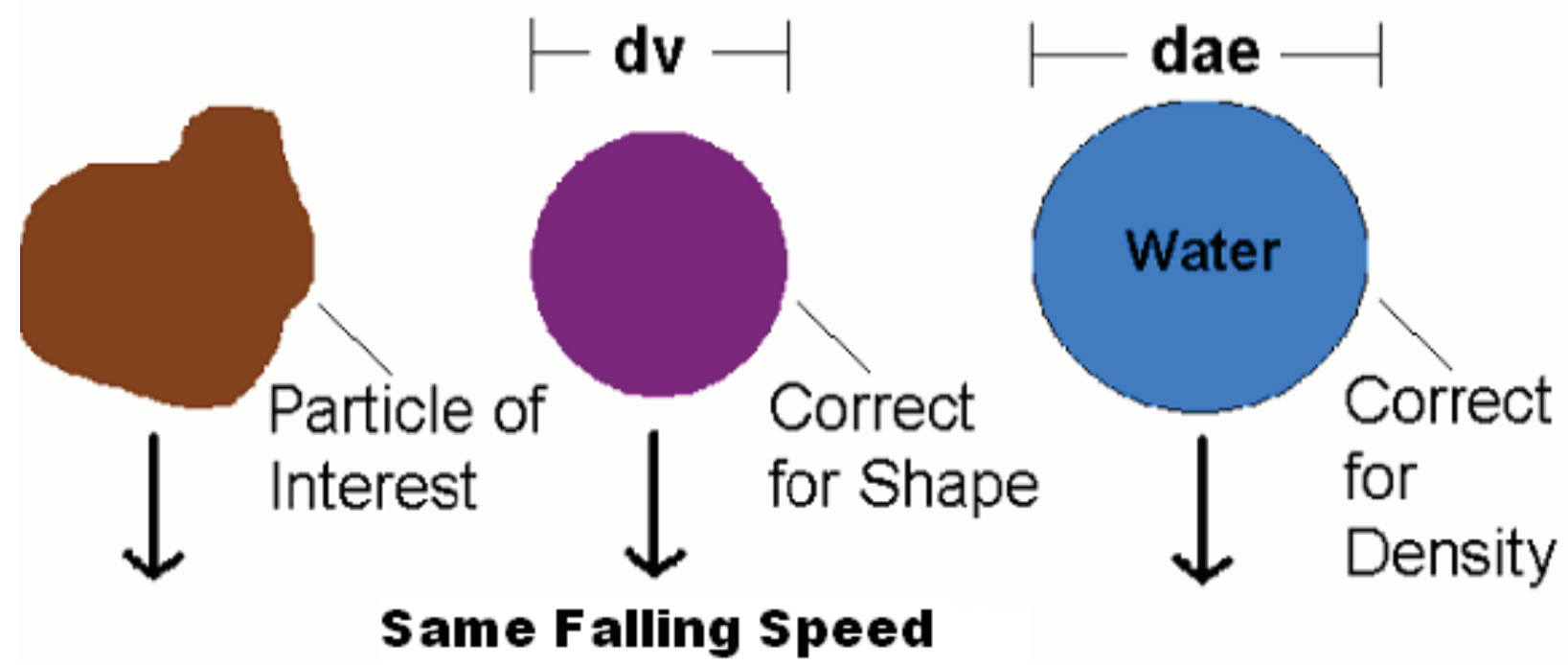

Figure 2. Settling velocity of test particle measured and compared to reference particle, unit density sphere. ${ }^{15}$

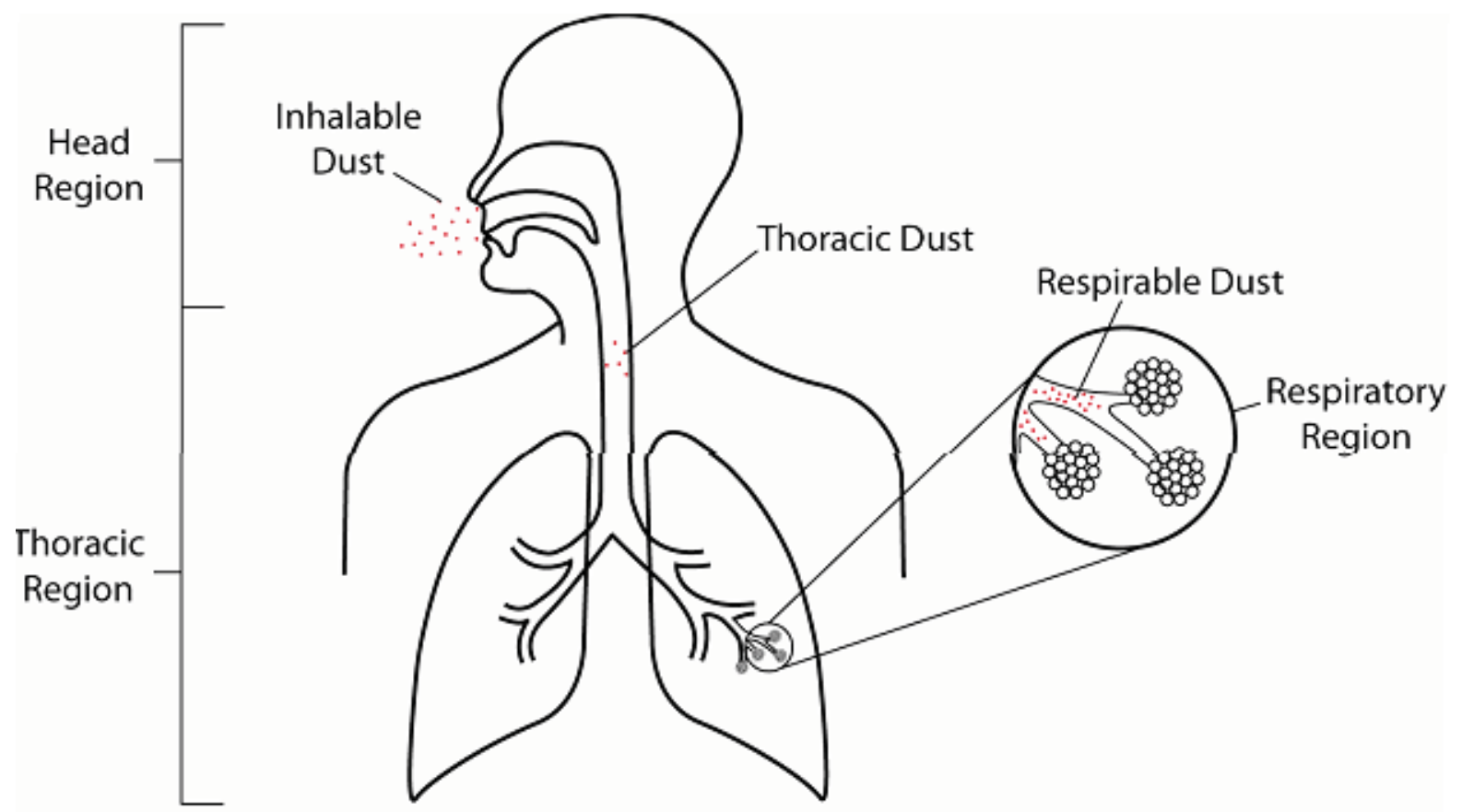

Adapted from Annals of American Conference of Gowernmental Hygienists, Vol. 11

Figure 3. Regional deposition of particulate matter in the lung. ${ }^{15}$ 


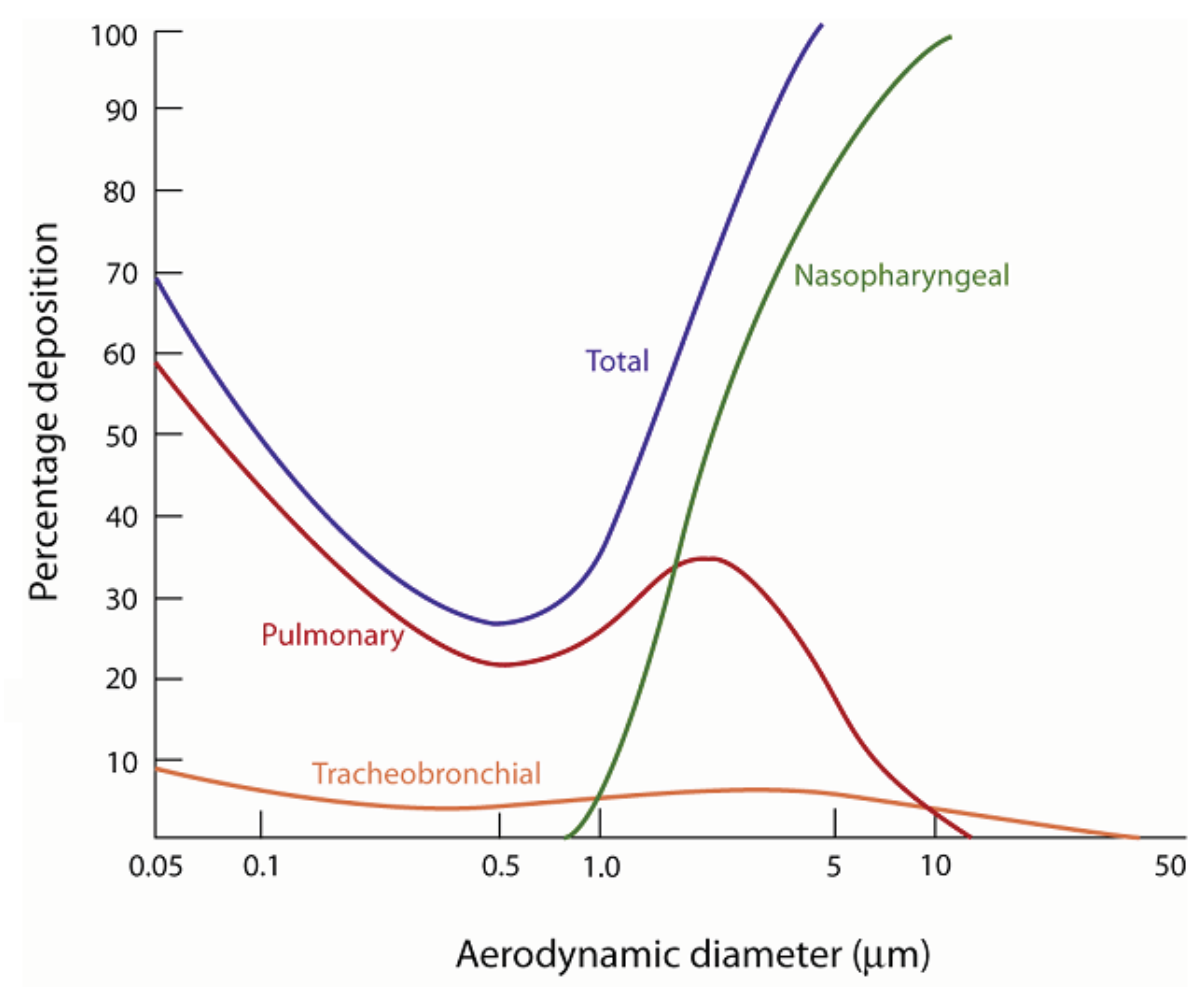

Figure 4. Site of deposition within the lung. ${ }^{15}$

The particle range that can penetrate beyond the terminal bronchioles to the gas exchange region is shown in Figure 5.

\begin{tabular}{c|c|}
$\begin{array}{c}\text { AED, } \\
\mu \mathrm{m}\end{array}$ & $\begin{array}{c}\% \\
\text { Penetrating }\end{array}$ \\
\hline 0 & 100 \\
2 & 91 \\
4 & 50 \\
6 & 17 \\
8 & 5 \\
10 & 1 \\
\hline
\end{tabular}

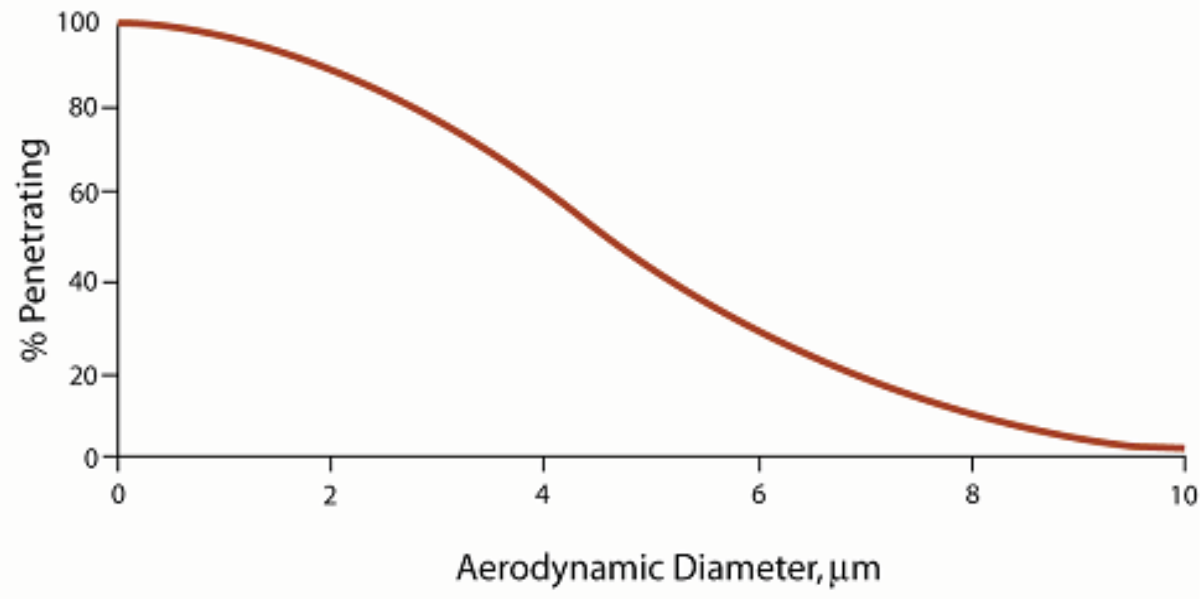

Adapted from Annals of American Conference of Gowernmental Hygienists, Vol. 11

Figure 5. Percent penetrating the lung by aerodynamic equivalent diameter. ${ }^{15}$ 
There are four mechanisms of particle deposition within the lung:

- Inertial impaction - The process whereby a particle moving in a gas stream is unable to remain in the streamline when the gas changes direction (turns). As a result, the particle strikes a stationary obstacle (e.g., surface in respiratory system) directly in its path and is removed from the air. ${ }^{15}$

- Interception - The process whereby a particle moving in a gas stream remains in that airstream but, because of its dimensions, strikes a stationary obstacle (e.g., surface in respiratory system) and is removed from the air. ${ }^{15}$

- Sedimentation (gravitational settling) - The process by which a particle in an airstream is pulled downward by gravity until it strikes a stationary obstacle (e.g., surface in respiratory system) and is removed from the air. ${ }^{15}$

- Diffusion - The process by which the molecules of two or more substances (very small particles having some molecular characteristics) gradually mix as a result of random thermal motion, will strike a stationary obstacle (e.g., surface in respiratory system), and be removed from the air. ${ }^{15}$

These mechanisms are shown in Figures 6, 7, 8, and 9, respectively.

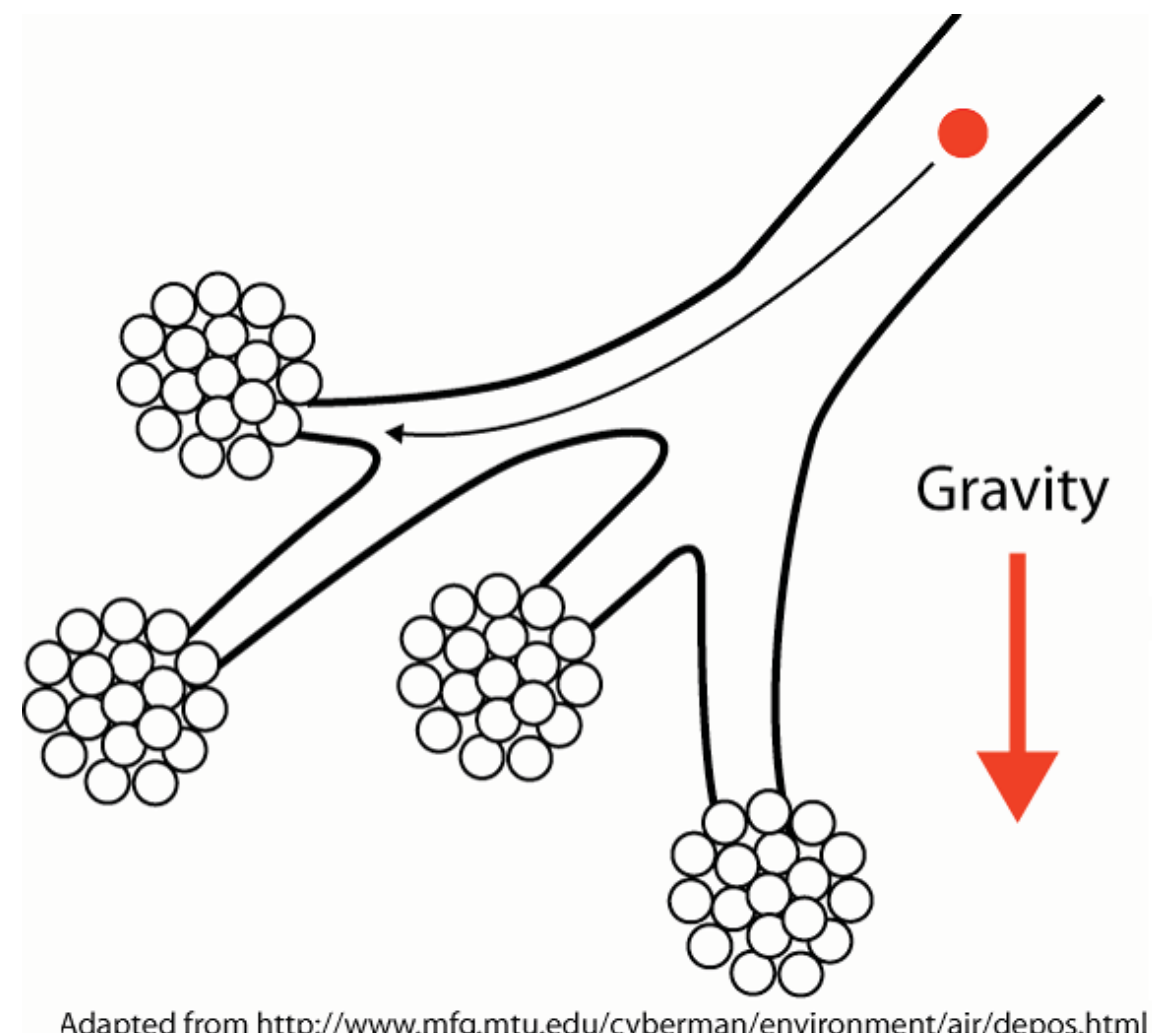

Figure 6. Inertial impaction - mechanism of particle deposition within the lung. ${ }^{15}$ 


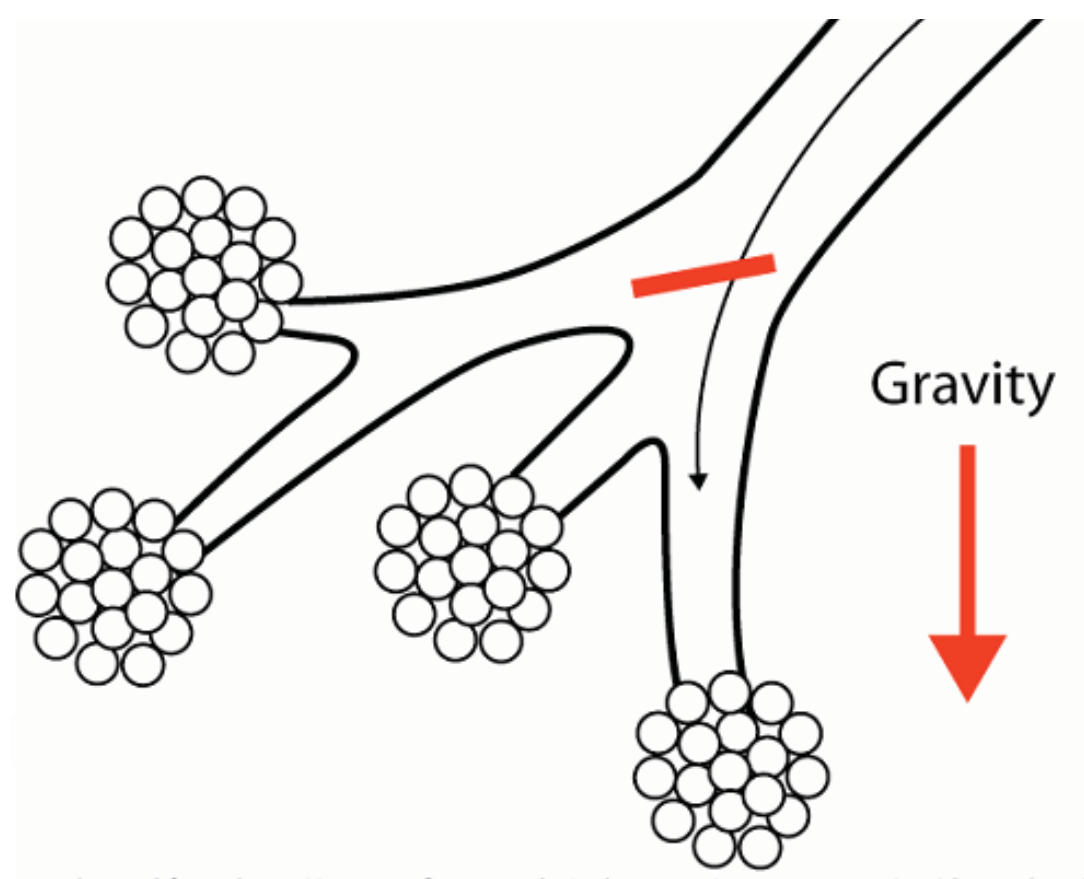

Adapted from http://www.mfg.mtu.edu/cyberman/environment/air/depos.html

Figure 7. Interception - mechanism of particle deposition within the lung. ${ }^{15}$

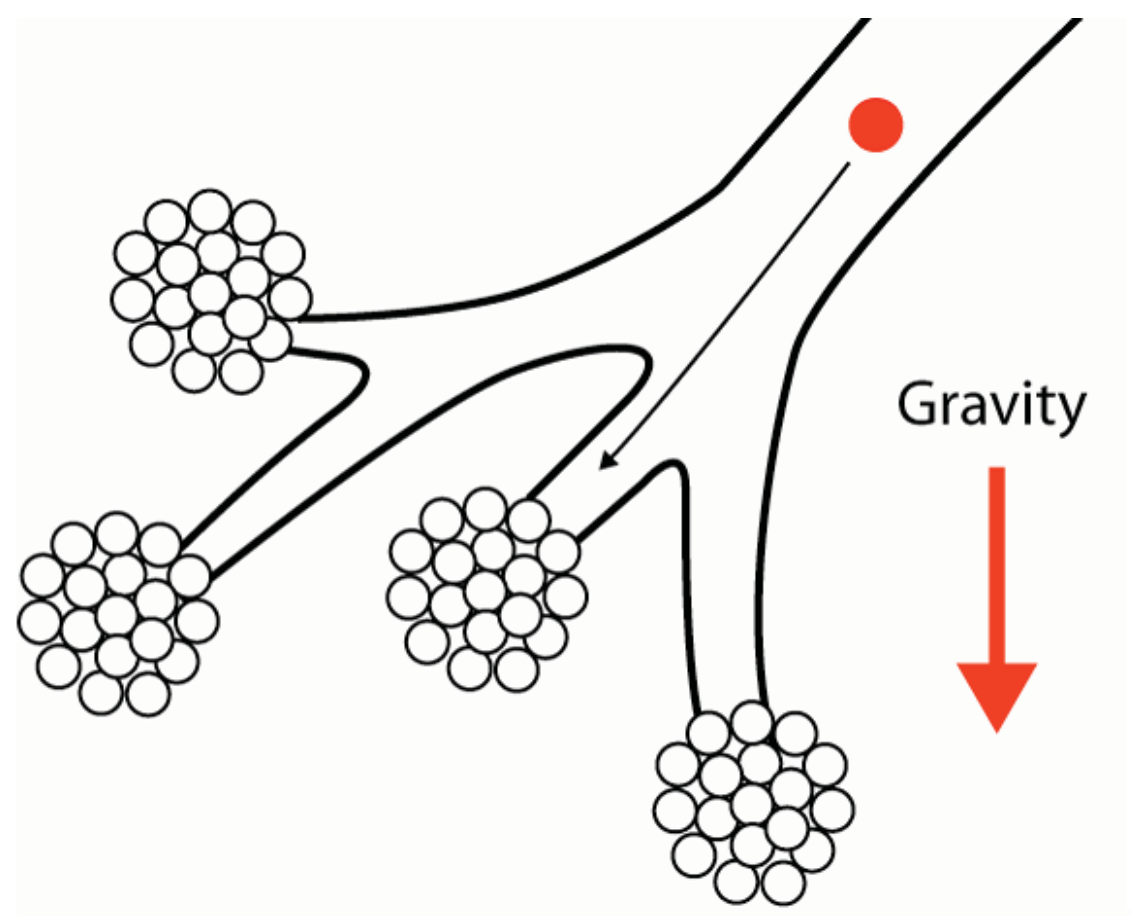

Adapted from http://www.mfg.mtu.edu/cyberman/environment/air/depos.html

Figure 8. Sedimentation (gravitational settling) — mechanism of particle deposition within the lung. ${ }^{15}$ 


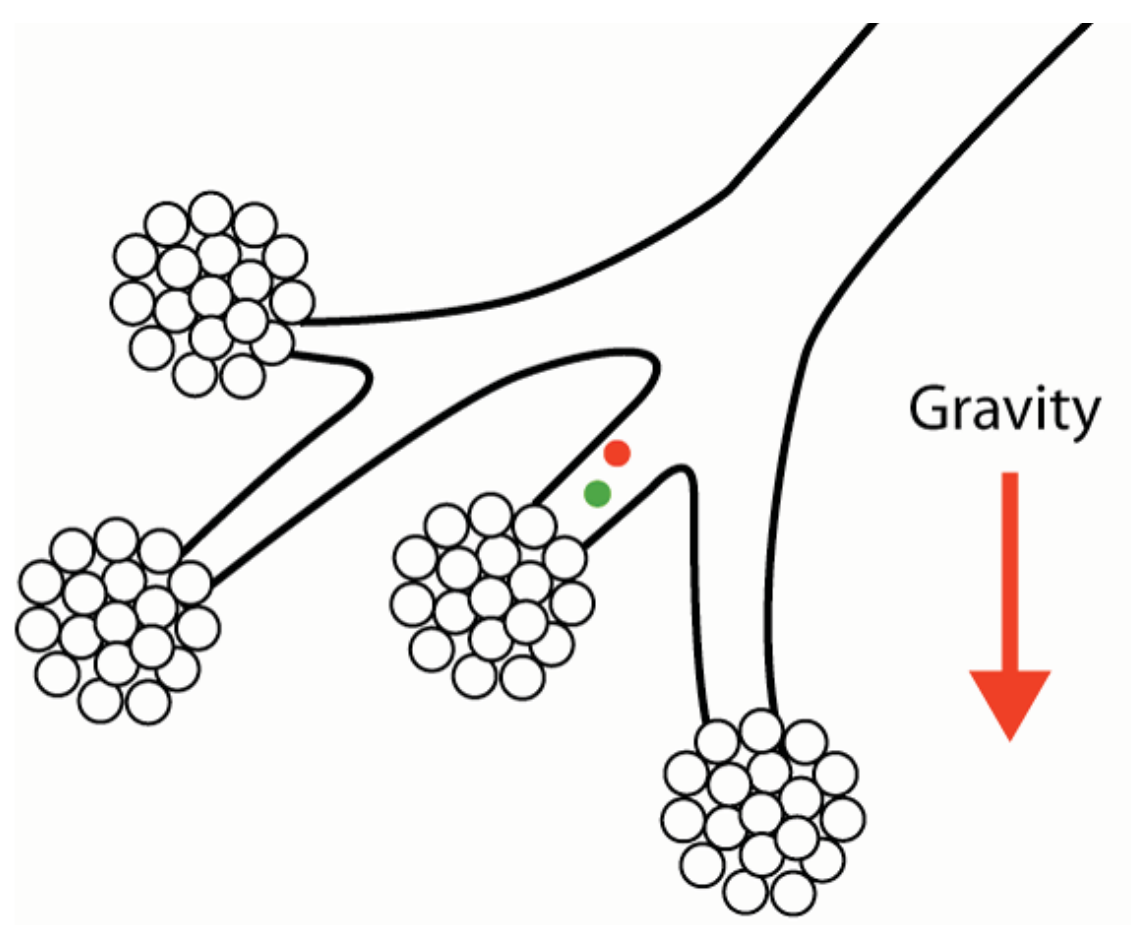

Adapted from http://www.mfg.mtu.edu/cyberman/environment/air/depos.html

Figure 9. Diffusion - mechanism of particle deposition within the lung. ${ }^{15}$

The histogram shown in Figure 10 displays a particle size distribution, referred to as a particle frequency distribution, which shows the percentage of particles found in each size range. Frequency can be plotted on the Y-axis, by number count, surface area, or mass. Within Figure 10 are the median, arithmetic mean, and mode, which can help characterize the arithmetic mass distribution. The median particle size, or mass median particle diameter, is the particle diameter that divides the frequency distribution in half. The arithmetic mean diameter, or mean diameter, is the arithmetic average particle diameter of the distribution. In particle size distributions, the mode is the particle diameter that occurs most frequently. (United States Environmental Protection Agency, "BCES: Module 3: Characteristics of Particle-Size Distribution"17)

Figure 2. Histogram of a Particle Size Distribution

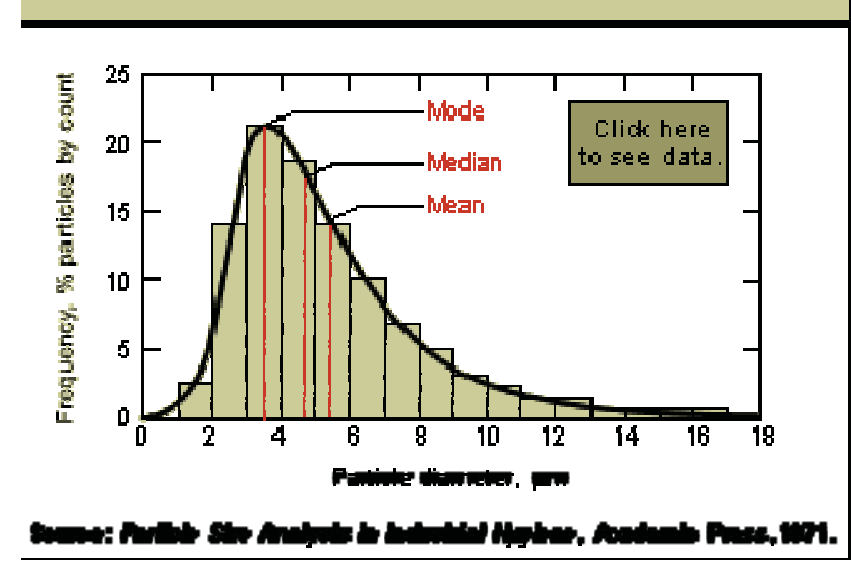

Figure 10. Histogram of a particle size distribution. ${ }^{17}$ 
When the particle diameters shown in Figure 10 are plotted on a logarithmic scale against the frequency of occurrence, a bell-shaped curve is generated, which is called a lognormal curve. The histogram shown in Figure 11 displays the particle size categories that are altered to produce equidistant ranges when plotted on a logarithmic basis. ${ }^{17}$

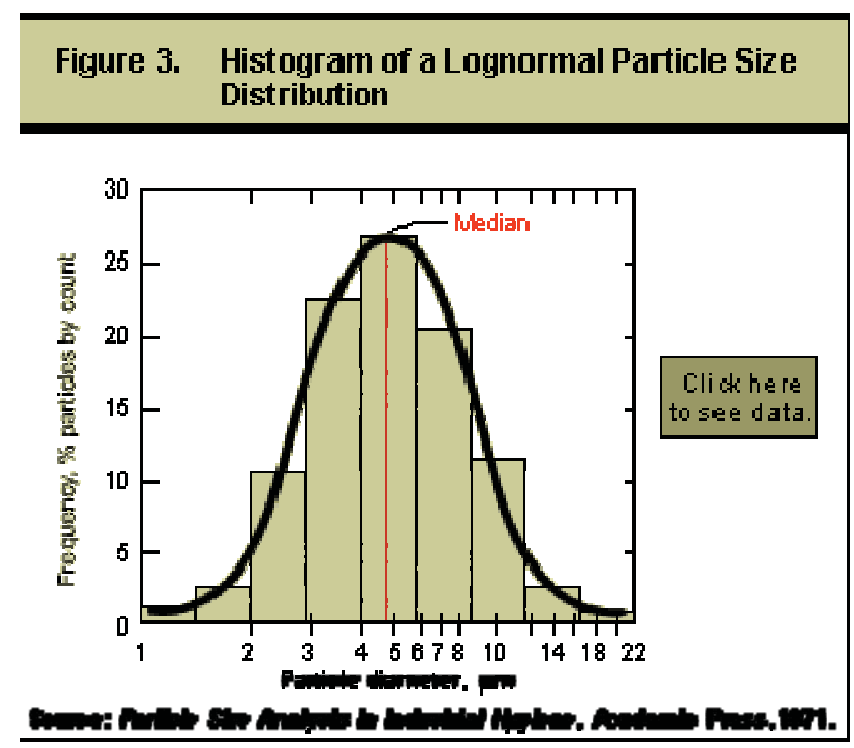

Figure 11. Histogram of a lognormal particle size distribution. ${ }^{17}$

When associating the logarithms of numbers, the terms, geometric mean diameter, and geometric standard deviation are substituted for arithmetic mean diameter and standard deviation. ${ }^{17}$

\subsection{Modeling}

Largely compartmentalized representations of buildings exist within DOE facilities. These configurations shine doubt on the validity of traditionally simplistic methods for evaluating and estimating LPFs. Also, laborious calculations of LPFs using extensive flow field analysis computer codes is illogical for routine evaluation. This section describes the application of a somewhat laborious, yet logical, method of calculating LPFs (Leonard and McClure $1998^{18}$ ), including quantitative insights based on facility modeling assumptions. The computer code of choice for modeling release scenarios and determining LPFs is the MELCOR code. DOE MELCOR LPF Guidelines ${ }^{19}$ state:

"Leak path factor analysis can be performed by developing and applying physically realistic modeling utilizing the U.S. Nuclear Regulatory Commission generalized mass transport and thermal-hydraulics computer program MELCOR 1.8.5-1.8.6, (Gauntt, Volume 1). ${ }^{20}$ MELCOR was initially developed at the Sandia National Laboratory under the sponsorship of the USNRC to assess reactor severe accident conditions. For the last several years, MELCOR has been used in the DOE complex to model release of radioactive airborne material from non-reactor facilities and structures. The leakage is usually expressed as a fraction of the amount considered available for release and is termed the Leak Path Factor. MELCOR is a fully integrated, engineering-level computer code whose primary purpose is to model the progression of accidents in light water reactor nuclear power plants. A broad spectrum of severe accidents phenomena in both boiling and pressurized water reactors is treated in MELCOR in a unified framework. MELCOR estimates fission product source terms and their sensitivities and uncertainties in a variety of applications." 
The MELCOR code is composed of a multitude of major modules, that when combined, model major systems and generally integrated interactions. DOE MELCOR LPF Guidelines state:

"Control Volume Hydrodynamics (CVH), in conjunction with the flow package (FL), evaluates mass and energy flows between control volumes; Flow Paths (FL), models in conjunction with the $\mathrm{CVH}$ package, the flow rates of gases and liquid water through the flow paths that connect control volumes; Heat Structures (HS), models the thermal response of heat structures and mass and heat transfer between heat structures and control volume pools and atmospheres. Treats Conduction, condensation, convection, and radiation, as well as degassing of unlined concrete; Radionuclide Behavior (RN), Models radionuclide releases, aerosol and fission product vapor behavior, transport through flow paths, allows for simplified chemistry, and describes the behavior of radioactive aerosols in containment building, and aerosol mechanics in the containment atmosphere such as particle agglomeration and gravitational settling, and the impact of engineered safety features on thermal-hydraulic and radionuclide behavior; Control functions (CF), evaluates user-specified "control functions" and applies them to define of control various aspects of the computation such as opening and closing of valves, controlling plot, edit, restart frequencies, and defining new plot variables; Tabular functions (TF), evaluates user-selected "tabular functions" to define or control various aspects of the computation such as mass and energy sources."

Using the MELCOR code to analyze the LPF for a facility requires the assessment of the boundary of the problem and modeling approach. The MELCOR code uses a control volume approach, subdividing the facility into control volumes and cells connected by flow paths. This process is referred to as nodalizing, as shown in Figure 12, and does not follow a specific rule, but rather is based on experience. Flow paths constitute doors, penetrations, and pathways to the outside environment. ${ }^{19}$

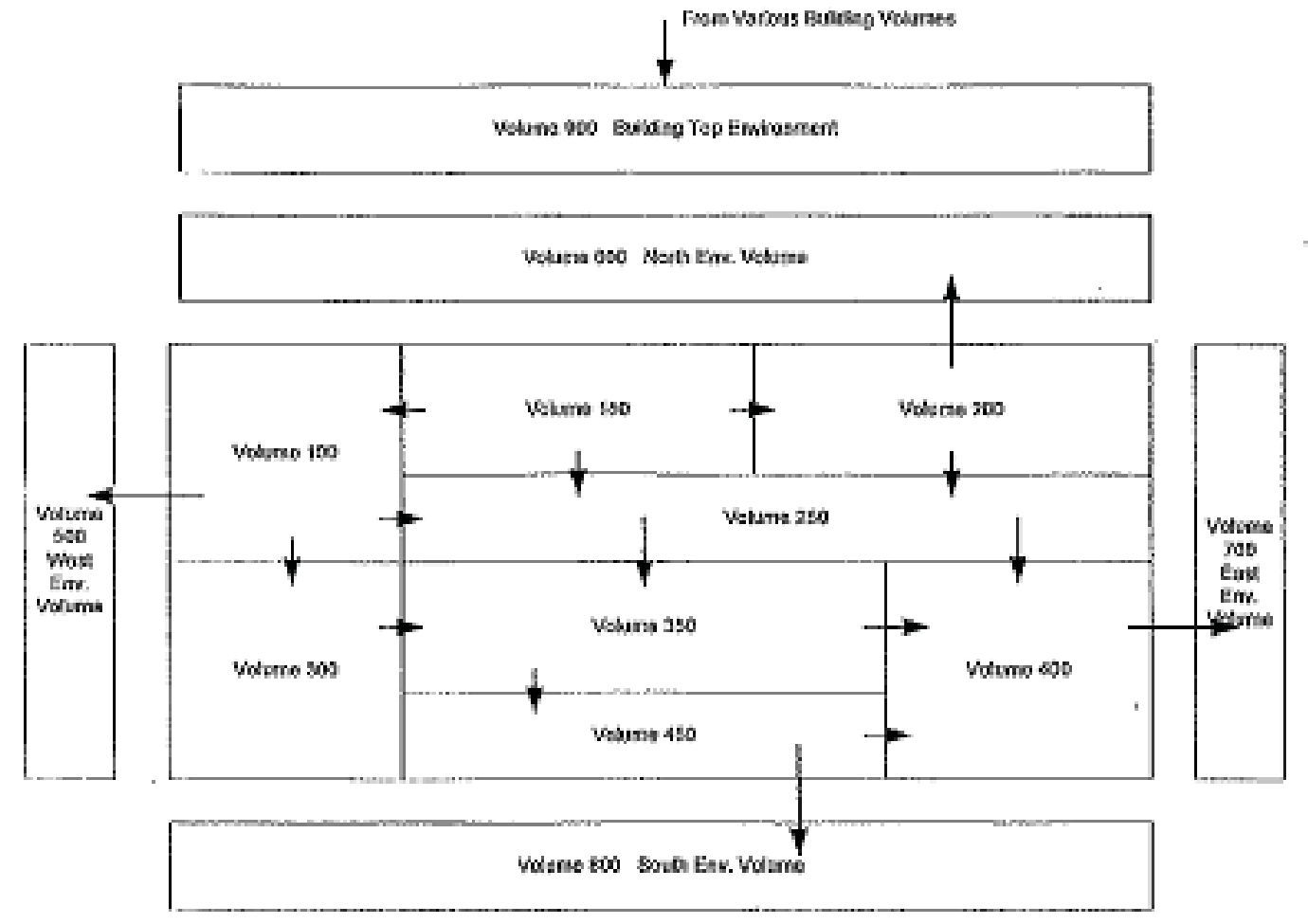

Figure 12. Nodalized schematic of control volumes and flow junctions. ${ }^{19}$ 
The modeling of ventilations systems can present a challenge whether or not the systems are seismically designed. Thus, an evaluation must be performed to assess the possible flows in and out of each control volume. Altogether it is not appropriate to model the entire ducting system, but as fixed flows, which can be designated to specify ventilation flow where necessary. ${ }^{19}$

A crucial flow path designation in LPF analysis is the evaluation of door gaps. Generally, it is assumed that doors have gaps around the entire door frame. For general analysis, gaps of approximately $0.00635-\mathrm{m}$ average, or a 1/4-in. average, can be assumed to calculate the closed door flow area. ${ }^{19}$

Furthermore, the modeling of environmental volumes, as shown in Figure 12, is very important because these volumes are used to compute the quantity of aerosolized material escaped from the building interior, thus yielding the LPF. As many environmental volumes as necessary may be modeled. These volumes act as sinks for the MELCOR code analysis and must be large enough to maintain constant environmental properties (i.e., pressure and temperature). Also, environmental volumes can be input to model filtration systems and ventilation supply and to characterize independent LPF contributions from various pathways to the outside environment. ${ }^{19}$

Air infiltration into and out of a facility is strongly affected by wind-driven differential pressures across the building (Shaffer and Leonard $1999^{21}$ ). The temperature and equivalent wind pressure applied to the environmental volumes, or boundary volumes, can be calculated. The necessary parameters are the wind speed and wind direction. The recommended wind speed is the same as that used in the consequence analysis to maintain consistency. Furthermore, with the wind speed and direction and environmental temperatures, it is possible to calculate the equivalent wind pressure using Equation No. 2. Equation No. 2

$$
\Delta \mathrm{P}=\mathrm{c}_{\mathrm{p}} \rho\left(\mathrm{v}^{2} / 2\right)
$$

Where:

$$
\begin{aligned}
& c_{p}=\text { pressure coefficient } \\
& \rho=\text { local air density } \\
& \mathrm{v}=\text { wind speed }
\end{aligned}
$$

Even though the true pressure differentials across the building due to wind conditions are quite small, they are considerable enough to promulgate the transport of aerosolized material within the building and to the outside environment. ${ }^{19}$

Furthermore, the MELCOR code input calls for a distribution of aerosolized particles. The most likely distribution, as described above, is lognormal, because particle size predominately extends over several orders of magnitude. The lognormal distribution of aerosolized particles used by the MELCOR code probability density function (PDF) is shown in Equation No. 3.

$$
\text { Equation No. } 3 \quad \operatorname{PDF}=\left[1 /\left(\sqrt{2} \pi \mathrm{d}_{\mathrm{p}} \ln (\sigma)\right)\right] * \mathrm{e}^{\left[\left(1 \ln 2\left(\mathrm{~d}_{\mathrm{p}} / \mathrm{d}_{\mathrm{m}}\right)\right) /(2 \ln 2(\sigma))\right]}
$$

Where:

$\mathrm{d}_{\mathrm{p}}=$ distributed variable parameter diameter

$\mathrm{d}_{\mathrm{m}}=$ volume-equivalent mass median particle diameter

$\sigma=$ geometric standard deviation.

With the PDF and maximum aerosol particle diameter, minimum aerosol particle diameter, volume-equivalent mass median particle diameter, and geometric standard deviation variables described above, a lognormal particle distribution can be built. ${ }^{19}$ 
Another MELCOR code input of importance is the amount of aerosolized material released in the facility. This input may be specified as a tabular function, tabular function module, with the amount of material input versus time. The amount of material may be specified as a unit weight, such as $1.0 \mathrm{~g}$ or $1.0 \mathrm{~kg}$. This is a convenient way to express the released material as a fraction of initial material, generalizing the release to any amount of material. The amount of material released in the facility could be a triangle, or a normalized rectangular distribution, as shown in Figure 13.

MELCOR LPF Guidance

Final Report

May 2004

Table 4-5. Rectangular Mass Spill Distribution

\begin{tabular}{|c|c|}
\hline \multicolumn{2}{|c|}{ Rectangular Mass Spill Disfribution } \\
\hline $\begin{array}{c}\text { Time } \\
\mathrm{s}\end{array}$ & $\begin{array}{c}\text { Spilled Mass } \\
\mathrm{kg}\end{array}$ \\
\hline 0.0 & 0.0 \\
\hline 1.0 & 0.0 \\
\hline 1.0 & 0.5 \\
\hline 3.0 & 0.5 \\
\hline 3.0 & 0.0 \\
\hline 5.0 & 0.0 \\
\hline
\end{tabular}

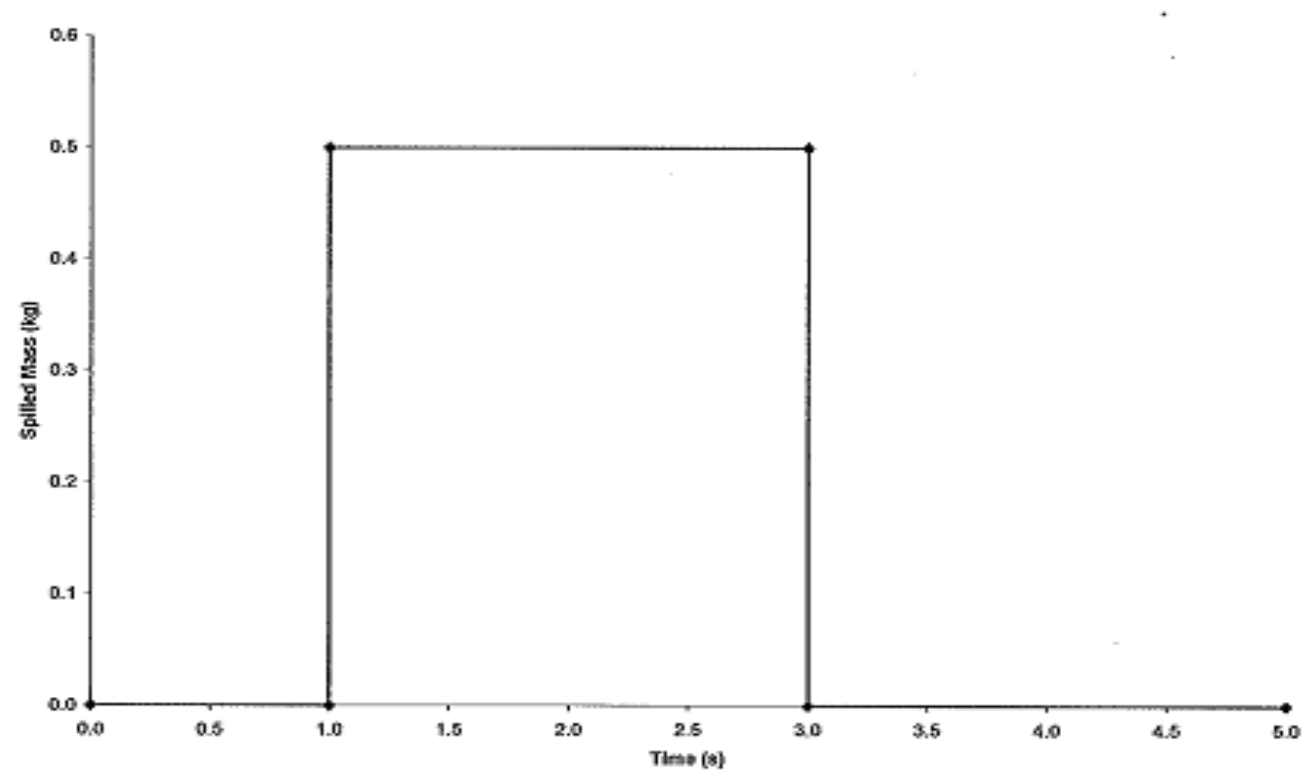

Figure 4-7. Rectangular Spilled Mass versus Time Distribution

One important aspect in the aerosol MELCOR input is the amount of material to be released as aerosol into a cell. The amount of aerosolized material initially present in a MELCOR cell contributes to the agglomeration (coagulation) of aerosol particles. If a large amount of material is present in a cell, the deposition of acrosol due to gravitational settling is enhanced.

Figure 13. Description of spill distribution. ${ }^{19}$

Applying a generalized unit mass is convenient and can be done as stated above. However, because the amount of mass that is released into air affects particle deposition, using the true value of mass injected into a control volume is recommended. ${ }^{19}$ 
Also, the MELCOR code can be used to model a fire by specifying the input of energy into a control volume of interest as described in DOE MELCOR LPF Guidelines and shown in Figures 14 and 15.

MELCOR LPF Guidance

Final Report

May 2004

\subsection{Fire Modeling}

Melcor cannot explicitly model the physics of a fire. A fire can be approximately modeled in MELCOR by simply adding mass and energy into a cell(s). Adding energy to the systemgenerates pressure and temperature in the cell(s), which in turn acts as a forcing condition causing leakage of the acrosolized mass present in the cell(s).

The fire modeling is accomplished by using a combination of MELCOR Control Functions (CF) and Tabular Functions (TF) modules which will enable the analyst to input the fire model parameter in a tabular form.

A recommended approach to use when modeling a fire is to add into a cell(s) a rated mass of material such as water vapor or other gas at a rated enthalpy. (ic.g., add minimal mass at fictionally high but properly accounted for enthalpy) In this way, the mass can be minimized and the product of the two rated entities becomes the desired energy input into the system.

If the intent is to input a fire burning at $1.0 \mathrm{Mw}$ for 30 minutes, Table $4-6$ shows the rated mass and enthalpy to generate the fite.

Table 4-6. Typieal Fire Input

\begin{tabular}{|c|c|c|c|}
\hline \multicolumn{4}{|c|}{ Typical Fire Input } \\
\hline Time & Mass & Enthalpy & Energy \\
\hline $\mathrm{s}$ & $\mathrm{kg} / \mathrm{s}$ & $\mathrm{J} / \mathrm{kg}$ & $\mathrm{W}$ \\
\hline 0.0 & 0.0 & 0.0 & 0.0 \\
\hline 300.0 & 0.0 & 0.0 & 0.0 \\
\hline 600.0 & 0.001 & $1.0 \mathrm{E}+9$ & $1.0 \mathrm{E}+6$ \\
\hline 2400.0 & 0.001 & $1.0 \mathrm{E}+9$ & $1.0 \mathrm{E}+6$ \\
\hline 2700.0 & 0.0 & 0.0 & 0.0 \\
\hline 5000.0 & 0.0 & 0.0 & 0.0 \\
\hline
\end{tabular}

Figure 4-9 shows the typical fire as given in Table 4-6.

The correct intensity of the fire and duration will be dependent upon a specific fire analysis. Generally, the more intense the fire, the higher the LPF, and the longer duration the fire, the higher the LPF. However, this is not always true. The analysts should run parametric studies to assess the influence of the varying inputs to understand the specific problem and determine the appropriate LPF.

Figure 14. DOE MELCOR LPF Guidelines describing fire modeling. ${ }^{19}$ 


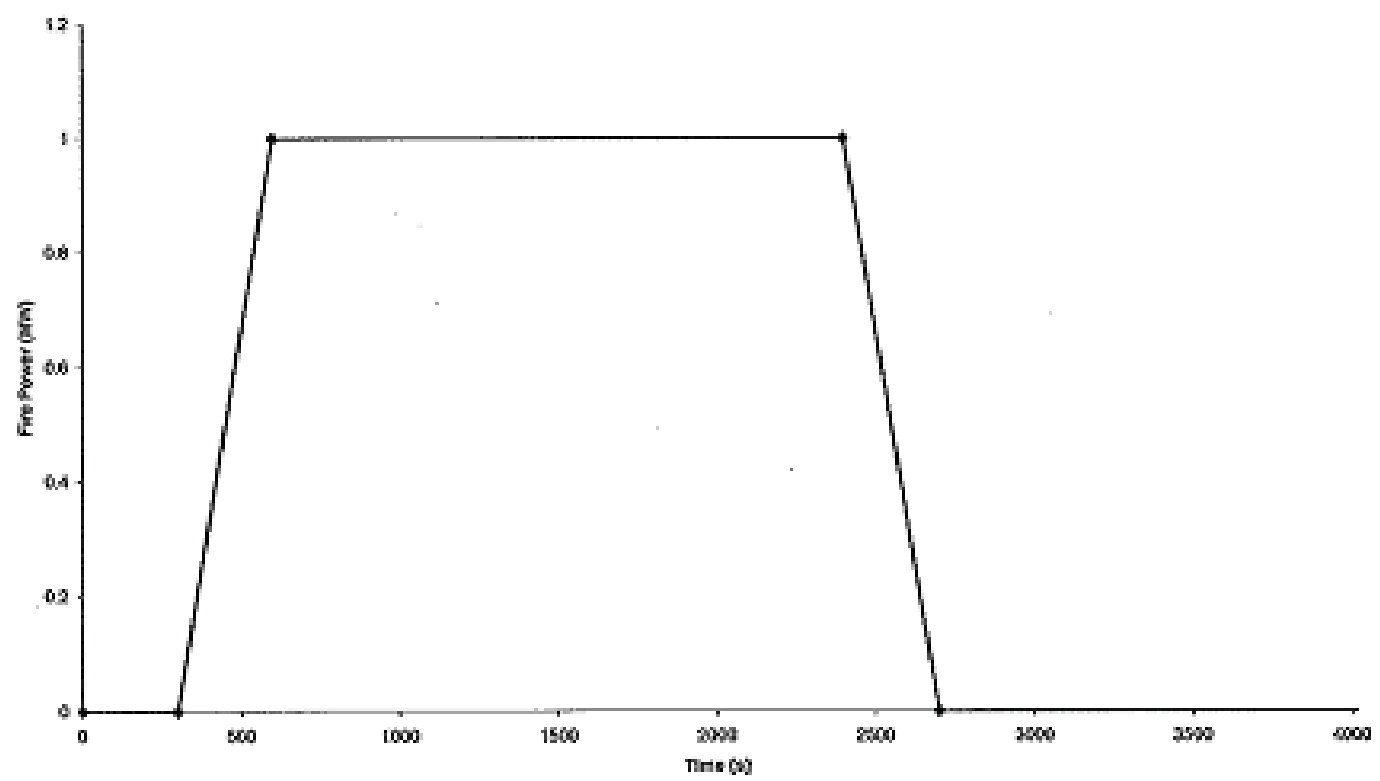

Figure 4-9. Typical Fire Input - Fire Power Versus Time

As mentioned above, MELCOR does not model the physics of the fire event, but uses an energy input to simulate the fire energy addition into a cell (volume). The actual fire analysis can produce the data requited to model the fire. The fire analysis could produce a temperature profile vs. time in the room; the analysts can try to reproduce that profile by running MELCOR, predicting an energy input into the cell and then adjusting until the temperature profile is similar to the one originally calculated by the actual fire analysis.

It has to be noted that instead of using the method mentioned above, the analyst could use the potential energy due to the combustible material. This will generate unrealistically high temperature in the fire cells, but it should be conservative.

During the combustion process for most of the fires encountered in accident analysis, the production of combustion gases can be neglected. The dominant mechanism to transport aerosols out of the fire cell are the convective flows which are driven by density gradients in the fire compartment and hot gas cxpansion early in the fire.

Figure 15. DOE MELCOR LPF Guidelines describing fire modeling (cont.). ${ }^{19}$

Various structures that model the heat transfer between adjacent volumes can be specified within the MELCOR code. However, such structures have little influence on the LPF because ventilation and flow tend to control the release, and typically, the amount of heat transferred to structures is nonexistent. The most crucial aspect of heat structure modeling is the ability to input surface area for aerosol interactions, especially horizontally facing upward structures that allow for aerosol mass deposition as the source is transported through the building. ${ }^{19}$ 
According to Polizzi, "The use of MELCOR offers a robust method to assess the amount of material that can be released because of accidents found in non-reactor nuclear facilities. Using the methodology presented in this paper, the chief benefit that can be found is the possible integration of source term evaluation and its consequence analysis. This work can be used as model for performing analyses for systems similar in nature where releases can propagate to the outside environment via filtered and unfiltered pathways. The methodology provides guidance to analysts outlining the essential steps needed to perform a sound and defensible analysis."

\subsection{Particle Characteristics}

Mueller ${ }^{8}$ states: "Radiological and chemical release source terms can vary by orders of magnitude depending on the characteristics of the material at risk, its primary containment, the facility and process characteristics including safety features and protective systems, and, the driving accident. Under the stable conditions generally assumed for atmospheric transport, reducing the source term by half can reduce by a comparable factor the distance at which radiation exposures are predicted, depending on the specific meteorological and other atmospheric transport parameters assumed. This knowledge can serve site staff both in developing plant features or procedures to ensure safety against plausible severe accidents and in planning for their occurrence."

As stated above, atmospheric transport depends on a multitude of characteristics. The characteristics of interest in this introduction are those that are involved in dry deposition. Dry deposition is the removal of particulates and gases at the air-surface interface (Schrader $2003^{22}$ ), in which a percentage of plume concentration is removed over length of transport due to removal processes associated with gravitational settling (Chamberlain $1953^{23}$ ). The primary release characteristics of major importance associated with dry deposition are the ST of the radionuclides and their physical and chemical characteristics. Particle characteristics include density, diameter, size distribution, chemical form, and gravitational settling. Density is used to calculate gravitational settling velocity. ${ }^{22}$ Diameter is predominantly considered the most important aspect when characterizing aerosol behavior (Sehmel $1974^{24}$ ). Particle settling velocity depends on diameter (i.e., smaller particles have longer transport times). When assessing size distribution small particle deposition velocity is dominated by Brownian motion, while larger particles are dominated by inertial impaction and gravitational settling. ${ }^{22}$

A polydisperse distribution may be described as a lognormal distribution. The differences in deposition velocities in association with chemical form are characterized by iodine and particulate. Due to the inertness of noble gases, deposition velocity and chemical transformations are assumed to be nonexistent. The chemical form of particulate is divided into the following three categories:

1. Highly-reactive elemental iodine

2. Slightly-reactive cesium, strontium, yttrium, and oxides

3. Nonreactive noble gases.

The gravitational settling velocities for small, less than or equal to $10 \mu \mathrm{m}$ and $7 \mathrm{~g} / \mathrm{cm}^{3}$, and large particles are deduced from their respective equations, and calculated for each particle size, as defined by the lognormal distribution. Implicit within these equations is the density of air $\left(\mathrm{g} / \mathrm{cm}^{3}\right)$, gravitational settling velocity $(\mathrm{cm} / \mathrm{s})$, diameter of the particle $(\mathrm{cm})$, and gravitational acceleration $\left(981 \mathrm{~cm} / \mathrm{s}^{2}\right){ }^{22}$

Furthermore, particle diameters that exceed $10 \mu \mathrm{m}$ and smaller particles with a high density have gravitational settling velocities that considerably increase the rate of particle deposition. Also, deposition velocities depend on air layers such as the depletion layer that is dominated by ground surface effects. ${ }^{22}$ Chemical form resistances to deposition $\left[\mathrm{R}_{\mathrm{c}}(\mathrm{s} / \mathrm{m})\right]$ in the transport layer are provided for the three categories of reactivity (non, no deposition; slightly, 2,000; highly, 200) as identified in Table 1. 
Table 1. Aerodynamic resistance to deposition in the transport layer. ${ }^{22}$

\begin{tabular}{|l|l|c|c|}
\hline \multicolumn{1}{|c|}{ Type } & \multicolumn{1}{|c|}{ Definition } & Examples & $\mathrm{R}_{\mathrm{c}}(\mathrm{s} / \mathrm{m})$ \\
\hline Nonreactive & Noble gases & $\begin{array}{c}\text { Helium, neon, argon, } \\
\text { krypton, xenon, and } \\
\text { radon }\end{array}$ & $\begin{array}{c}\text { No deposition is assumed } \\
\text { to occur }\end{array}$ \\
\hline Slightly reactive & Radioactive particulate & $\begin{array}{c}\text { Cesium, strontium, } \\
\text { yttrium, and oxides }\end{array}$ & 2,000 \\
\hline Highly reactive & Elemental iodine & $\mathrm{I}_{2}$ & 200 \\
\hline
\end{tabular}

Other possible characteristics of interest include hygroscopicity, absorbing or attracting moisture from the air (Dictionary.com ${ }^{25}$ ); impaction; diffusiophoresis; and diffusion.

\section{MATERIALS AND METHODS}

The subject of this study was based on MFC-785, Hot Fuel Examination Facility (HFEF), at the Materials and Fuels Complex. A scenario, MFC-785-R1, was followed. HFEF, a three-floor building, is analyzed where one room, the truck lock, is selected to have a release of a radioactive aerosol consisting of a given amount of activity and equivalent mass as identified in Table 2.

Table 2. Material-at-risk in curies and equivalent mass.

\begin{tabular}{|c|c|c|}
\hline Hazardous Material & $\begin{array}{c}\text { MAR } \\
(\mathrm{Ci})\end{array}$ & $\begin{array}{c}\text { Mass } \\
(\mathrm{g})\end{array}$ \\
\hline Cs-137 & $3.83 \mathrm{E}+05$ & 441.3 \\
\hline Sr-90 & $2.59 \mathrm{E}+05$ & 188.4 \\
\hline Pu-239 & $7.44 \mathrm{E}+05$ & 1.4 \\
\hline Am-241 & $3.43 \mathrm{E}+02$ & 10.1 \\
\hline
\end{tabular}

The scenario was chosen to show the propagation of multiple flow paths from the truck lock to other rooms within HFEF and to the environment. The first step taken in this study was to create a MELCOR code mathematical model of the facility to analyze and then assess the LPFs.

To build a model, HFEF had to be analyzed through facility structural and architectural drawings. HFEF was then nodalized by subdivision into control volumes (cells). The environmental volumes were also modeled. The control volumes are shown in Figure 16 and identified in Table 3 and assumed to be fully confined where the only flow path to the environment is through a filtered heating, ventilation, and air conditioning (HVAC) system. This assumption is based on pressure differential, given that the exit door on the south side of the corridor faces a positive pressure when compared to the corridor volume. 


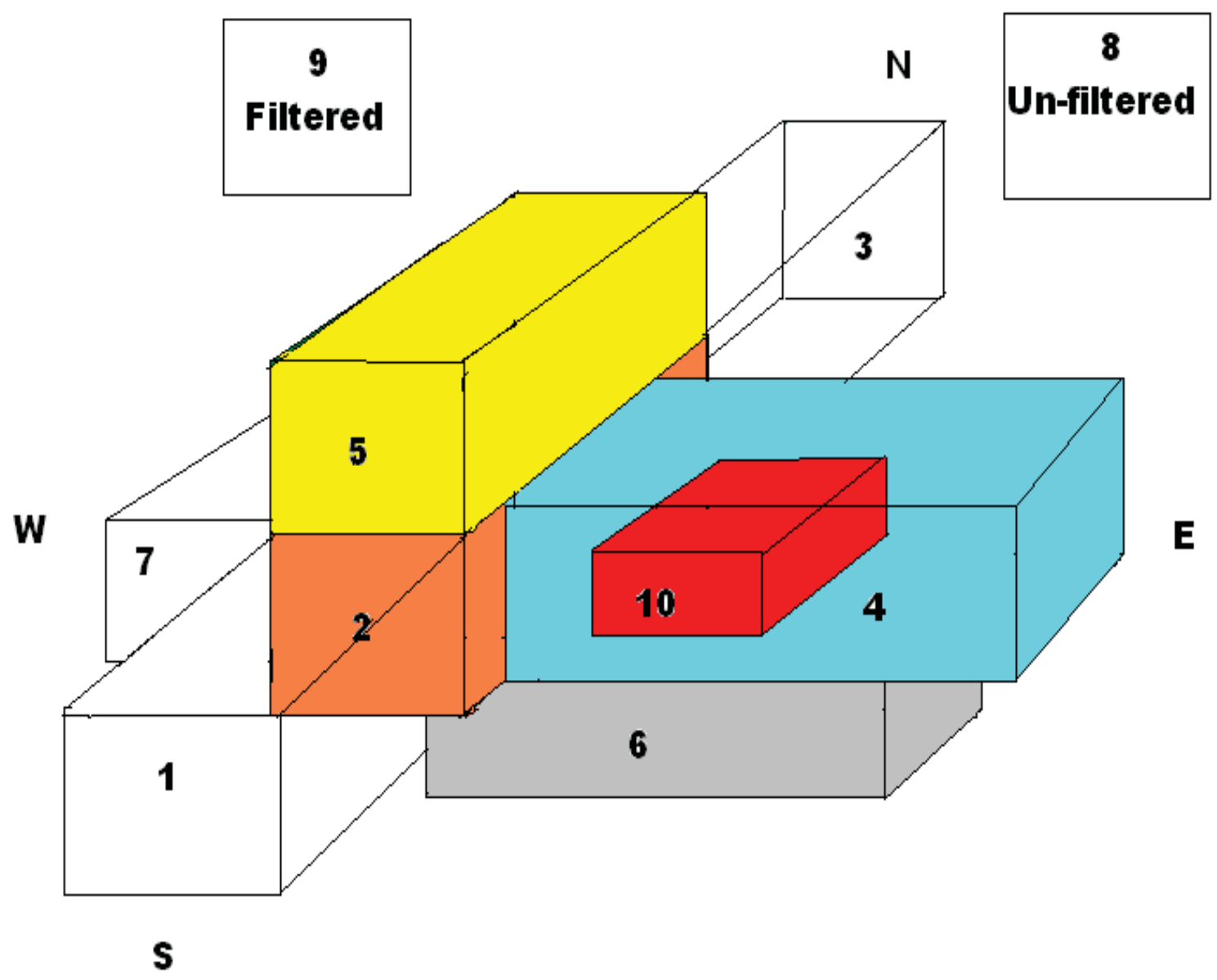

Figure 16. Three-dimensional model of the facility of interest.

Table 3. Description of control volumes.

\begin{tabular}{|l|c|}
\hline \multicolumn{1}{|c|}{ Control Volumes } & $\begin{array}{c}\text { Volume } \\
\left(\mathrm{m}^{3)}\right.\end{array}$ \\
\hline South environmental & $1 \times 10^{8}$ \\
\hline Truck lock & 1151.8 \\
\hline North environmental & $1 \times 10^{8}$ \\
\hline Corridor & 9,238 \\
\hline High bay & 15,642 \\
\hline Cask tunnel & 380.6 \\
\hline West environmental & $1 \times 10^{8}$ \\
\hline Filtered HVAC system & $1 \times 10^{8}$ \\
\hline Unfiltered HVAC system & $1 \times 10^{8}$ \\
\hline Decontamination cell & 424.8 \\
\hline
\end{tabular}


Table 4. Flow paths (from center elevation to center elevation) and the limiting flow path areas.

\begin{tabular}{|c|c|c|}
\hline \multicolumn{2}{|c|}{ Flow Path } & Limiting Flow Path Area \\
$\left(\mathrm{m}^{2}\right)$
\end{tabular}

The flow paths identified in Table 4 are assumed to flow from point of center elevation to point of center elevation. In determining flow areas, door gaps were evaluated and an assumption of 1/4 in. around the door frame was assumed based on a range from 1/8 to $1 / 2 \mathrm{in.}$ Values were also input to account for the movement through the door gaps and out the door gaps, such as 1.5 for contraction and expansion of the flow paths and 1.8 to represent the two 90 -degree bends of the door frame. The limiting flow path areas identified in Table 4 are the smallest flow path areas within each flow path segment. The last three flow paths identified in Table 4 represent the HVAC system and employ arbitrary flow path areas.

Next, the incident wind direction was based on the prevailing wind direction at the Materials and Fuels Complex of south-west. This direction is represented by a 45-degree vector at two magnitudes: $4.47 \mathrm{~m} / \mathrm{s}$, corresponding to approximately the $50 \%$ worst-case scenario; and $1.04 \mathrm{~m} / \mathrm{s}$, corresponding to approximately the $95 \%$ worst-case scenario $\left(\mathrm{GDE}-438^{26}\right)$. Both these cases are shown in Figure 17. 


\section{S to $\mathrm{N}$}

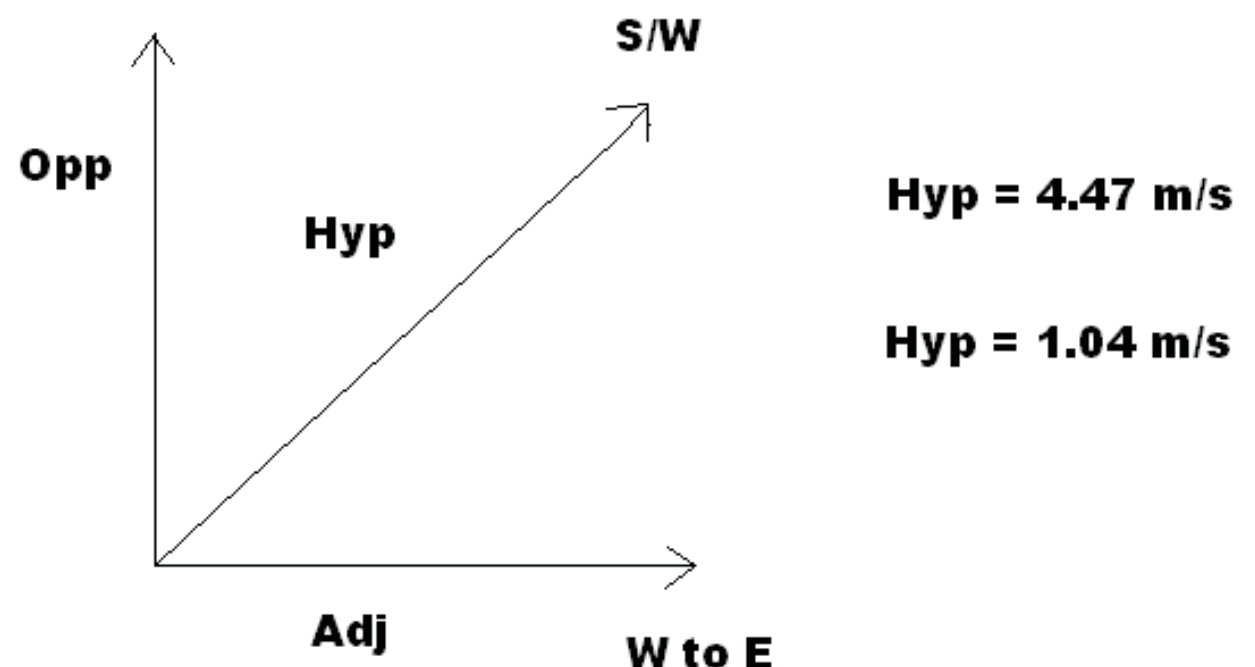

Where the south-to-north vector is represented by Opp. and calculated by:

- $\operatorname{Sin} 45^{\circ}=$ Opp. $/ 4.47 \mathrm{~m} / \mathrm{s}$

- Opp. $=3.15 \mathrm{~m} / \mathrm{s}$

- $\operatorname{Sin} 45^{\circ}=$ Opp. $/ 1.04 \mathrm{~m} / \mathrm{s}$

- Opp. $=0.75 \mathrm{~m} / \mathrm{s}$.

Figure 17. Vector components of the prevailing wind.

Given the 45-degree incidence, it is known that Adj. equals Opp. for both $4.47 \mathrm{~m} / \mathrm{s}$ and $1.04 \mathrm{~m} / \mathrm{s}$ and is thus $3.15 \mathrm{~m} / \mathrm{s}$ and $0.75 \mathrm{~m} / \mathrm{s}$, respectively.

Next, the boundary and initial conditions, such as the temperature and equivalent wind pressure applied to the environmental volumes, were calculated.

The local air pressure due to wind condition was calculated using Equation No. 2 with the inputs identified in Table 5.

Table 5. Typical building wind pressure coefficients.

\begin{tabular}{|l|c|}
\hline \multicolumn{1}{|c|}{ Parameter } & Input \\
\hline Upwind pressure coefficient & 0.7 \\
\hline Downwind pressure coefficient & -0.4 \\
\hline Side and top of building & -0.35 \\
\hline
\end{tabular}


Using the wind pressure coefficients identified in Table 5 and an assumed environmental volume temperature of $294.26 \mathrm{~K}\left(70^{\circ} \mathrm{F}\right)$, local air density of $1.2 \mathrm{~kg} / \mathrm{m}^{3}$, and an $4,700-\mathrm{ft}$ elevation adjusted atmospheric pressure of 85,219 $\mathrm{Pa}$, the resulting wind pressure is identified in Tables 6 and 7.

Table 6. Delta $\mathrm{P}$ and absolute pressure for the environmental volumes - normal atmospheric pressure set at $85,219 \mathrm{~Pa}(12.36 \mathrm{psia})$ and wind speed of $3.15 \mathrm{~m} / \mathrm{s}$.

\begin{tabular}{|l|c|c|}
\hline \multicolumn{1}{|c|}{ Parameter } & $\begin{array}{c}\text { Delta P } \\
(\mathrm{Pa})\end{array}$ & $\begin{array}{c}\text { Absolute Pressure } \\
(\mathrm{Pa})\end{array}$ \\
\hline Upwind side of building & 4.16 & 85,223 \\
\hline Downwind side of building & -2.4 & 85,217 \\
\hline West side of building & 4.16 & 85,223 \\
\hline Top of building & -2.1 & $85,216.9$ \\
\hline
\end{tabular}

Table 7. Delta $\mathrm{P}$ and absolute pressure for the environmental volumes - normal atmospheric pressure set at $85,219 \mathrm{~Pa}(12.36 \mathrm{psia})$ and wind speed of $0.75 \mathrm{~m} / \mathrm{s}$.

\begin{tabular}{|l|c|c|}
\hline \multicolumn{1}{|c|}{ Parameter } & $\begin{array}{c}\text { Delta P } \\
(\mathrm{Pa})\end{array}$ & $\begin{array}{c}\text { Absolute Pressure } \\
(\mathrm{Pa})\end{array}$ \\
\hline Upwind side of building & 0.23 & $85,219.2$ \\
\hline Downwind side of building & -0.11 & $85,218.9$ \\
\hline West side of building & 0.23 & $85,219.2$ \\
\hline Top of building & -0.12 & $85,218.9$ \\
\hline
\end{tabular}

The HVAC flow rates from control volumes 1 to 2,6 to 10 , and 10 to 8 were provided within facility literature as $3.15 \mathrm{~m}^{3} / \mathrm{s}$ and $1.7 \mathrm{~m}^{3} / \mathrm{s}$, respectively. The flow rates from control volumes 4 to 8 and 5 to 9 were input into the model based on a conservative value of 24 volume exchanges per day.

Then, the aerosol particles were modeled using the lognormal distribution of aerosolized particles used by the MELCOR code (PDF) as shown in Equation No. 3. The minimum diameter was set to an arbitrary value of $0.01 \mu \mathrm{m}$ and the mean mass diameter was set to 5- $\mu \mathrm{m}$ AED with a geometric standard deviation of two. Using Equation No. $5,{ }^{13}$ the maximum geometric diameter was calculated by normalizing the diameter to $10-\mu \mathrm{m}$ AED for each radionuclide identified in Table 8 .

Equation No. $5 \quad \mathrm{D}_{\mathrm{AED}}=\left(\mathrm{D}_{\mathrm{g}}\left[\rho_{\mathrm{p}}\right]^{0.5}\left[\mathrm{C}_{\mathrm{c}, \mathrm{e}} / \mathrm{C}_{\mathrm{c}, \mathrm{a}}\right]^{0.5}\right) / \alpha$

Where:

$\rho_{\mathrm{p}}=$ particle density $\left(\mathrm{g} / \mathrm{cm}^{3}\right)$

$\mathrm{C}_{\mathrm{c}, \mathrm{e}}=$ cunningham slip factor corresponding to volume equivalent diameter

$\mathrm{C}_{\mathrm{c}, \mathrm{a}}=$ cunningham slip factor corresponding to the aerodynamic equivalent diameter

$\alpha=$ aerodynamic shape factor. 
Table 8. Density, aerodynamic equivalent diameter, and geometric diameter of the specific radionuclide released.

\begin{tabular}{|c|c|c|c|}
\hline Radionuclide Released & $\begin{array}{c}\text { Nominal Density } \\
\left(\mathrm{kg} / \mathrm{m}^{3}\right)\end{array}$ & $\begin{array}{c}\text { AED } \\
(\mu \mathrm{m})\end{array}$ & Geometric Density \\
\hline Sr-90 & 2,640 & 10 & 6.2 \\
\hline Cs-137 & 1,930 & 10 & 7.24 \\
\hline Pu-239 & 19,840 & 10 & 2.24 \\
\hline Am-241 & 12,000 & 10 & 2.89 \\
\hline Total Release & 2,311 & 10 & 2.50 \\
\hline
\end{tabular}

After the variables were input and the deck was built, the input file was run through melgen.exe and a restart file was written. Then, the input file was run through melcor.exe and an output file was created. The output file was then analyzed using a plotting program.

\section{RESULTS AND DISCUSSION}

\subsection{Modeling}

A hazard scenario was chosen and the facility of interest within the scenario was modeled using the MELCOR code. Within the model, a source release of MAR equivalent mass was initiated with the assumption that $100 \%$ was aerosolized and $100 \%$ was respirable. Using input flow parameters, the MELCOR code then propagated the source through stated control volumes via stated flow paths, which included those leading to the environment. The fraction of MAR equivalent mass that escaped the building through the environmental flow paths and entered the specified environmental volumes was quantified. A ratio of the mass escaped to the total mass initiated was developed and an LPF was calculated. Also, because a ST can be respirable or nonrespirable, the LPF must be respirable or nonrespirable. Therefore, care must be used to apply the proper diameter range in the LPF calculations to maintain consistency within the applicable ST calculation. Figure 18 shows an LPF for each radionuclide and a total release of all radionuclides for the total facility, as represented by Figure 16, at a primary wind speed of $4.47 \mathrm{~m} / \mathrm{s}$. Figure 18 also shows that when each particle is normalized to a maximum AED of $10 \mu \mathrm{m}$, that each source displays the same LPF, thus allowing continuity of the MAR variable within a hazard scenario. 


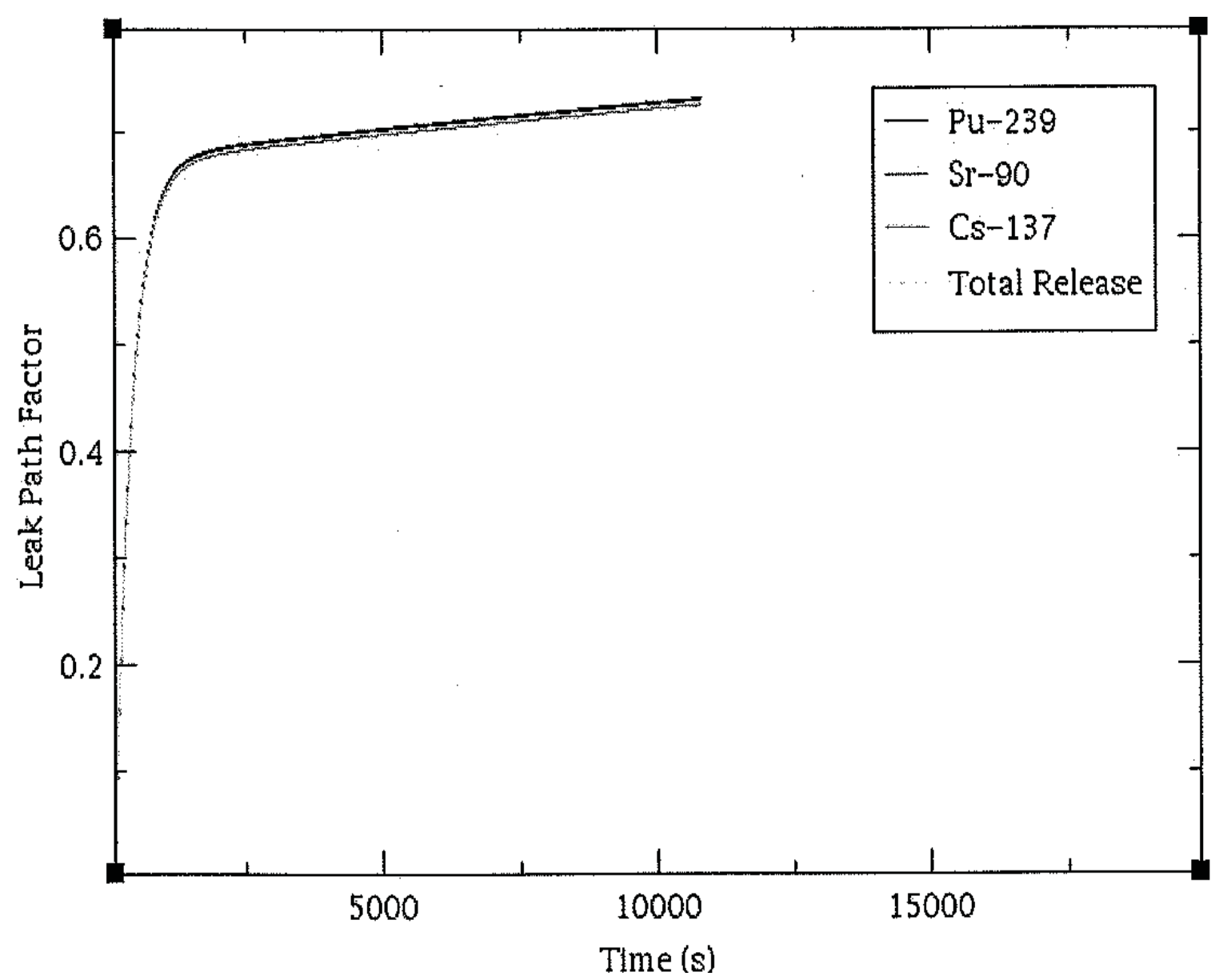

Figure 18. Leak path factors for the entire facility over time.

Figure 19 shows the total release peak in the truck lock at $0.664 \mathrm{~kg}$, and then return to near zero as the material propagates throughout the model. Approximately $66 \%$ of the material exits the truck lock through the closed rollup door and enters the north environmental volume; $15 \%$ of the material exits the truck lock, entering the high bay; $15 \%$ of the material exits the truck lock, entering the corridor; and approximately zero of the material enters the tunnel. The remaining $4 \%$ of the material can be assumed to be plated out. It can be seen that the direct release from the truck lock to the north environmental control volume drives this scenario. Also, these data show a large discrepancy between the model and the $0.5 \times 0.5$ assumption for the scenario. The model shows that almost no material remains in the truck lock with a range of $15 \%$ to $66 \%$ of the material exiting the truck lock into various other rooms. However, the assumption represents a highly simplified setup, where $50 \%$ is assumed to remain in the truck lock while $50 \%$ enters the environment. So, given the difference in models, the LPF shown in Figure 18 of $72 \%$ cannot be reasonably compared to the assumed LPF of $50 \%$. 


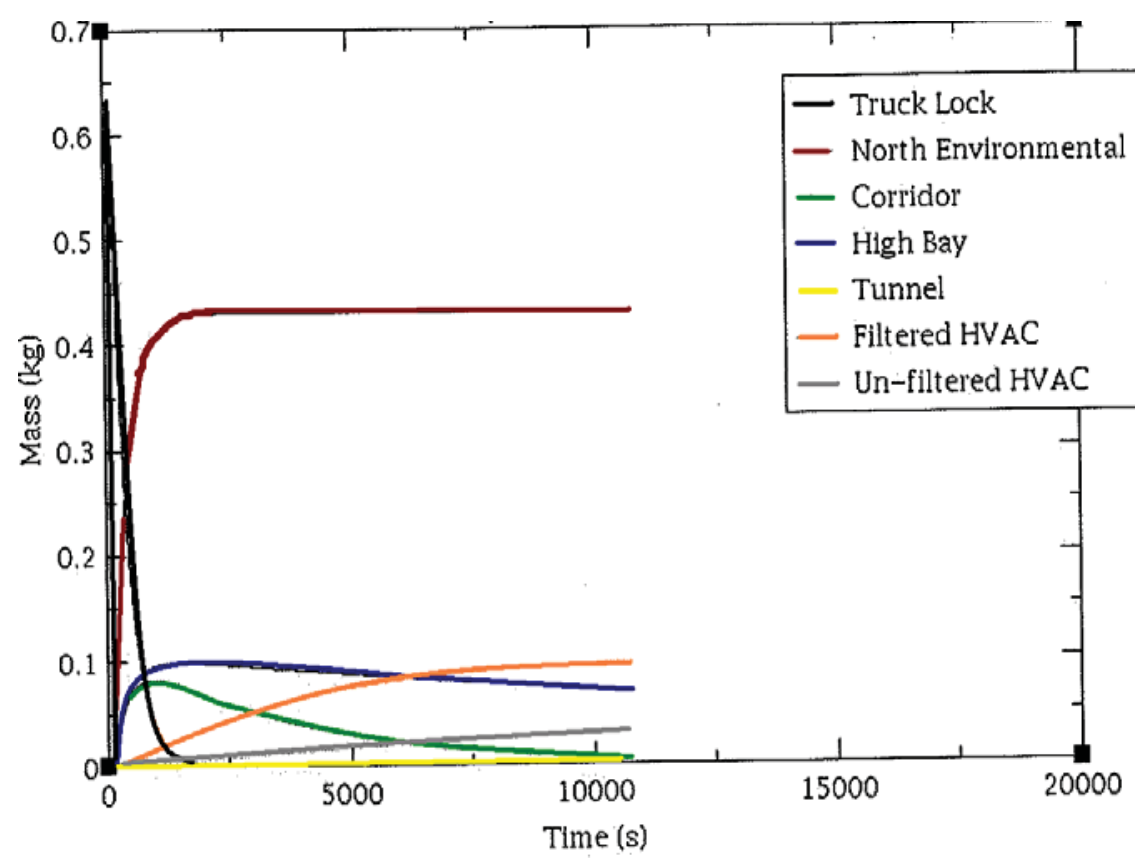

Figure 19. Mass in atmosphere for the entire facility over time.

To address these differences, a simplified version of the truck lock was modeled, which also represents a worst-case release scenario as it represents a direct release to the environment. This version treats the truck lock as a confined room with the same flow paths in, but only one flow path exiting the room, through the closed rollup door into the north environmental volume, as shown in Figure 20. Now, the same model can be used to reasonably compare data and the assumed LPF of $50 \%$ can be compared to the modeled factor. A respirable LPF of approximately $100 \%$, nearly double the assumed value, is shown in Figure 20. Also, as a note, this graph shows an LPF of $40 \%$ for a release of all particle sizes.

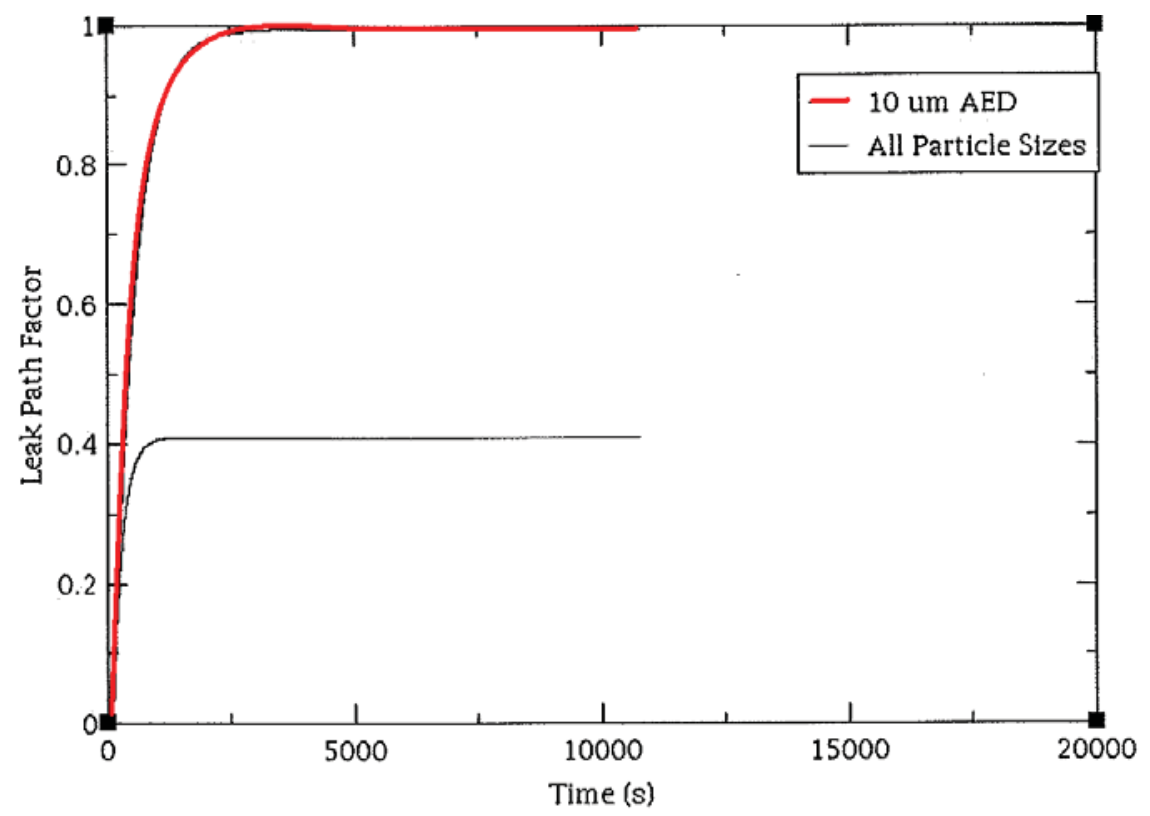

Figure 20. Leak path factor from the simplified truck lock model for the respirable range and all particle sizes at $4.47 \mathrm{~m} / \mathrm{s}$. 
Another sub-model represents a release from the confined truck lock, with the same flow paths in, but with one exiting flow path through the closed doors into the corridor, as shown in Figure 21. This model represents a confined room with one exiting flow path, of specified flow area that enters the corridor volume. As shown in Figure 21, approximately 50\% of the material exits the truck lock and enters the corridor volume. This is the one scenario where the $0.5 \times 0.5$ assumption shows validity.

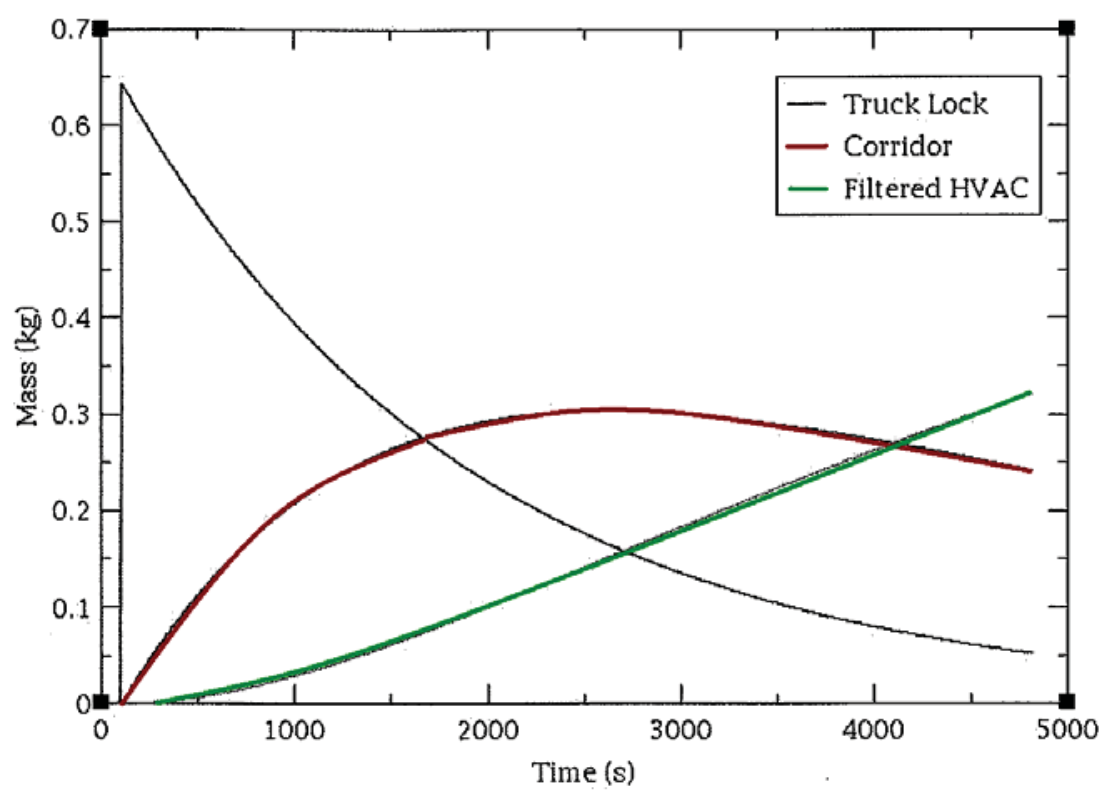

Figure 21. Mass in atmosphere over time.

Aside from Figure 21, the experimental results for a primary wind speed of $4.47 \mathrm{~m} / \mathrm{s}$ do not add validity to the $0.5 \times 0.5$ assumption. In fact, they show that the assumption is not conservative enough. However, an assumption could be made that by slowing the incidental wind speed and thus decreasing the pressure differential, the LPF would also decrease. So, the wind speed was reduced to $1.04 \mathrm{~m} / \mathrm{s}$ and two scenarios were modeled: a release in the truck lock for the main model (Figure 16), as shown in Figure 22; and a release in the truck lock with one exiting flow path through the closed rollup door into the north environmental volume, as shown in Figure 23.

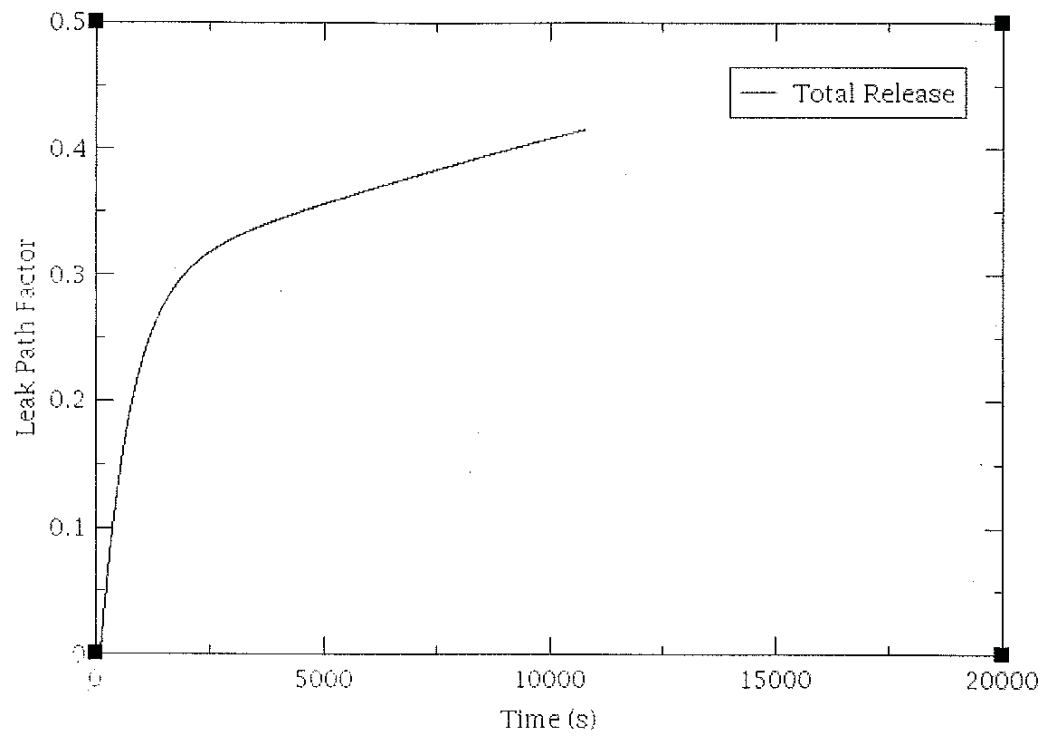

Figure 22. Release in truck lock over total facility at $1.04 \mathrm{~m} / \mathrm{s}$. 


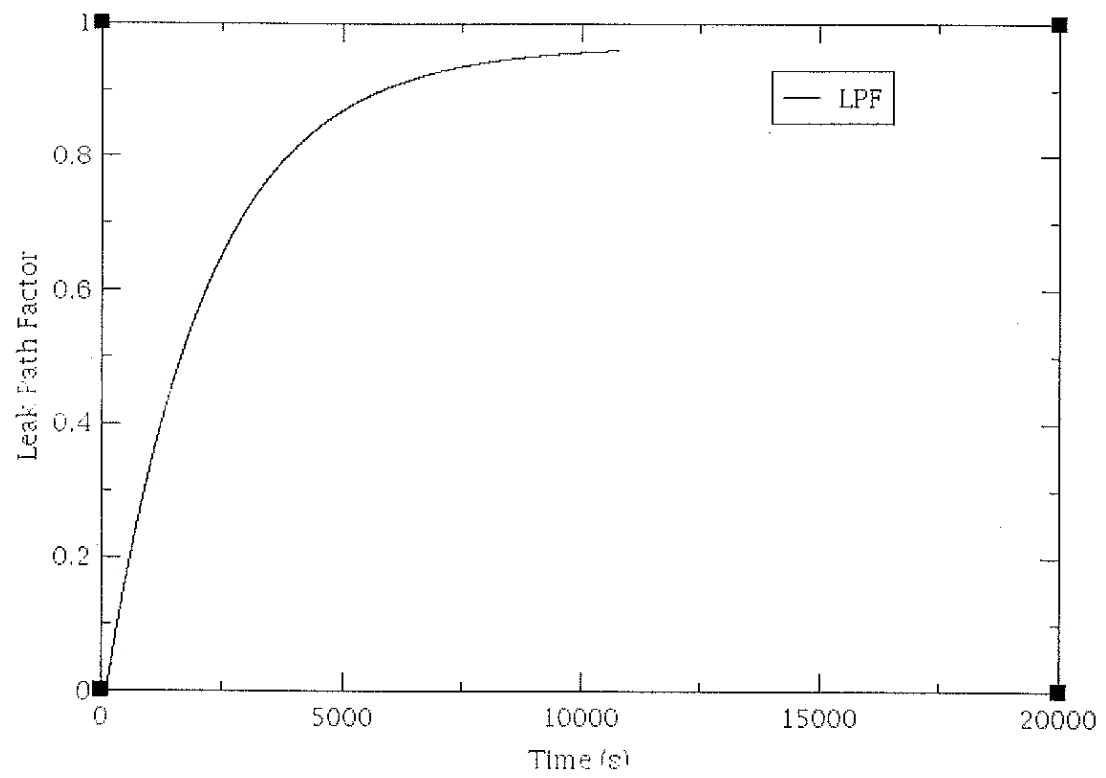

Figure 23. Release in truck lock to the north environmental volume at $1.04 \mathrm{~m} / \mathrm{s}$.

The $0.5 \times 0.5$ assumption provides an estimated LPF of $50 \%$ for this scenario, and with the lower wind speed, the experimental data in Figure 22 seems to support it. However, while this graph may seem to support the $50 \%$ assumption, the air flow dynamics within the facility are not properly accounted for, leaving the assumption far from supported. The LPF of $42 \%$ shown above actually represents $1.2 \%$ staying in the truck lock, $23 \%$ entering the corridor, 30\% entering the high bay, and $30 \%$ entering the north environmental volume, as shown in Figure 24.

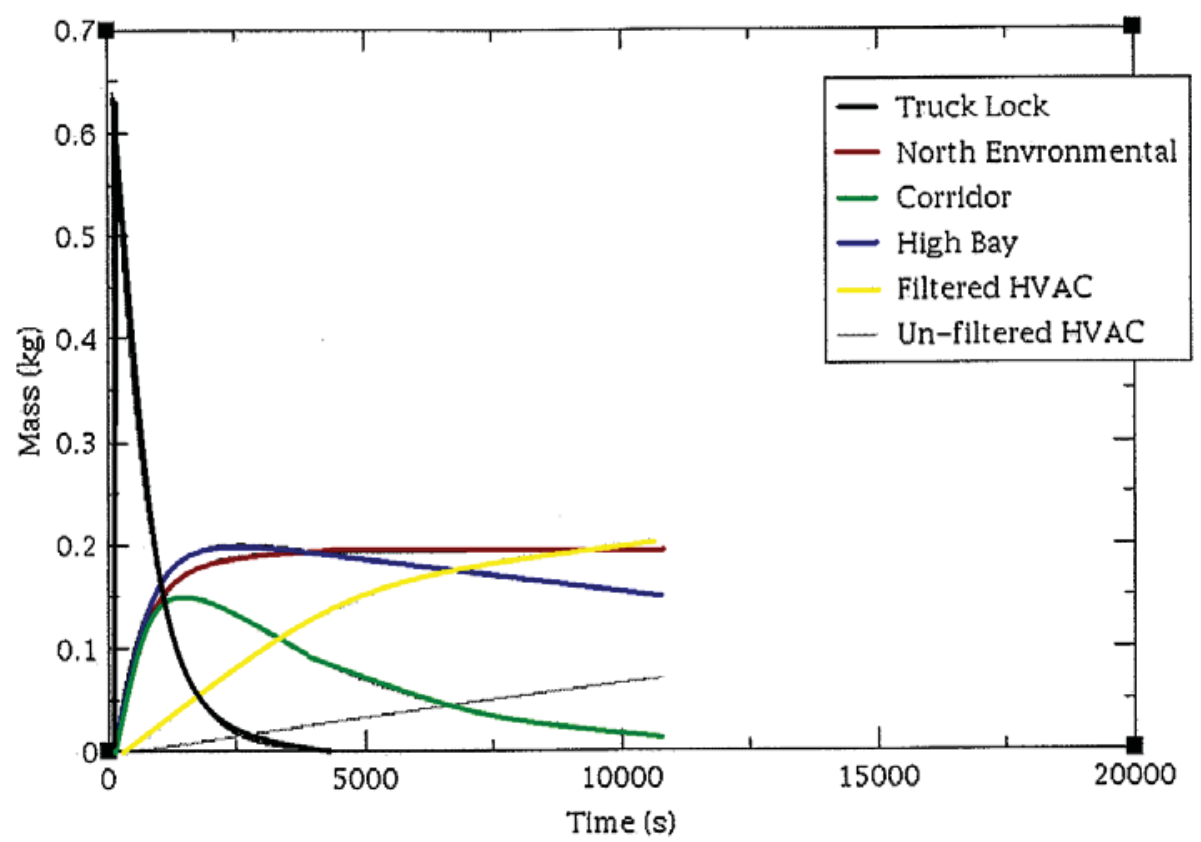

Figure 24. Amount in atmosphere for truck lock release over the main model at $1.04 \mathrm{~m} / \mathrm{s}$. 
Figure 24 also shows the most significant difference in lowering the incidental wind speed to $1.04 \mathrm{~m} / \mathrm{s}$, the nearly $20 \%$ decrease in the amount of material released into the north environmental control volume. So, lowering the wind speed appeared to add strength to the $0.5 \times 0.5$ assumption, until air flow dynamics were compared. Next, the simplified models were compared at the lowered wind speed, as shown in Figure 23.

Now, the assumed LPF of 50\% can be compared to the modeled factor. Figure 24 also shows a respirable LPF of approximately $98 \%$, nearly double the assumed value, once again, decreasing the strength of the $0.5 \times 0.5$ assumption.

The assumption is referred to as the $50 \times 50$ assumption and is based on the fractionation of the source by each enclosure within a facility of interest for which the ST moves through. DSA-003-HFEF, Chapter 3, Subsection 3.4.4.3.2, assigns an LPF value of 0.5 for each enclosure and states: "...it is assumed that $50 \%$ of the contaminants plate out in the main cell, $50 \%$ of that remaining plates out in the ducts and pipes, and $50 \%$ of what is left plates out in the building. So the fraction of the contaminants originally in the cell atmosphere following the accident that actually makes it to the outside is $(50 \% \times 50 \% \times 50 \%)=0.125,{ }^{\prime 10}$

Also, in cases where the LPF accounts for HVAC flow, there may be a range of applicable values. For example, the air ventilated from the corridor control volume is filtered through a bank of high-efficiency particulate air filters, which cut the material in air by a factor that equals the high-efficiency particulate air filtration efficiency, thus decreasing the LPF. For the model assumed in this study, when the arbitrary HVAC surface areas remain constant, with the HVAC air flow values removed, the LPF is decreased to approximately $65 \%$, as shown in Figure 25.

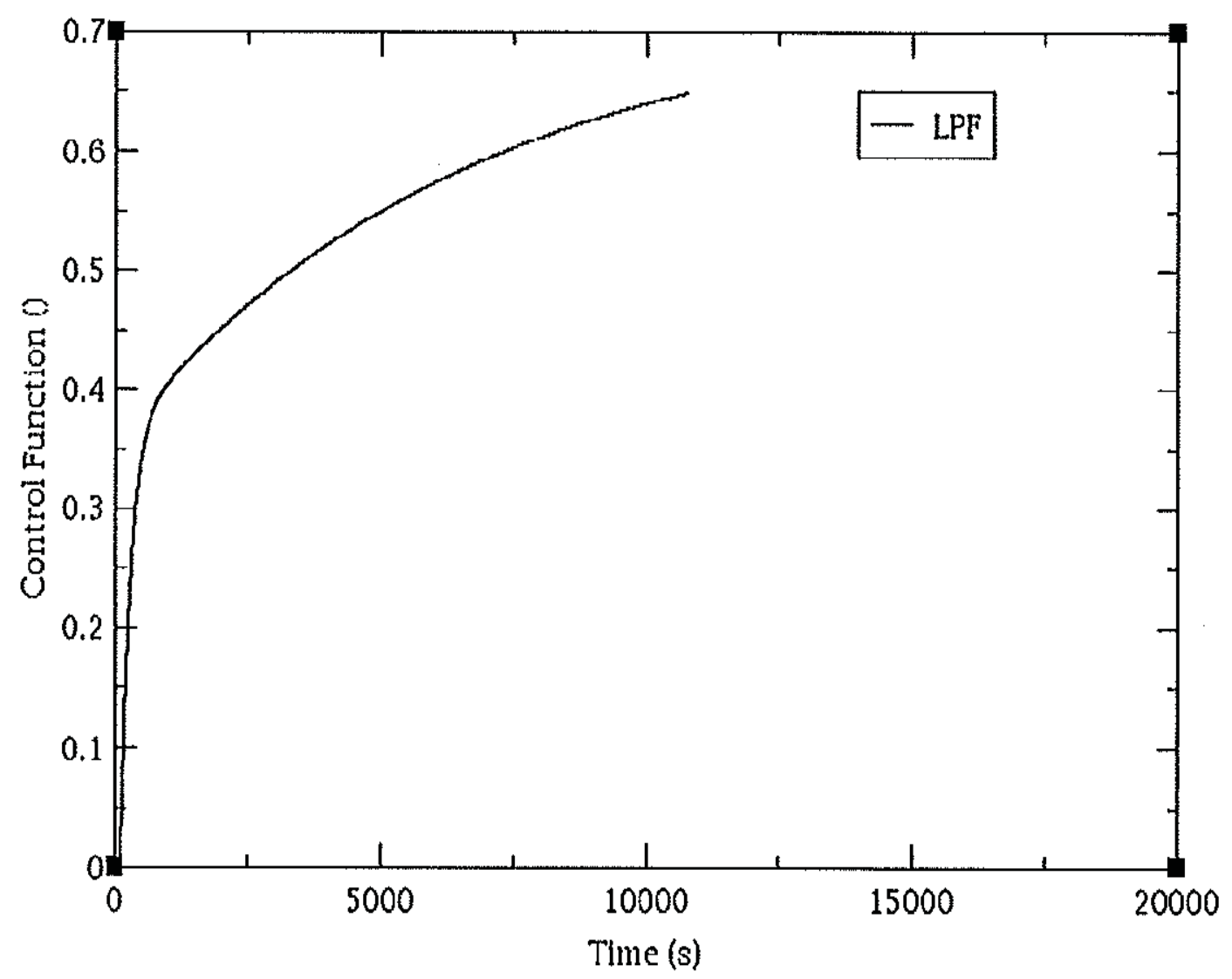

Figure 25. Leak path factor given no active heating, ventilation, and air conditioning air flow. 
For this model, if the HVAC system went down, and given the respirable size range, the particles would predominately remain suspended in air rather than settling out; therefore, the LPF would be dominated by pressure differentials. Furthermore, these pressure differentials could increase or decrease the LPF depending on whether the active HVAC air flow is more than or less than the passive air flow. Figure 26 displays the fluctuation of mass within the atmospheres of specific control volumes. As shown, the mass entering the north control volume is decreased to approximately $0.24 \mathrm{~kg}$, with the mass entering the high bay and corridor volumes increasing to approximately 0.2 and 0.13 , respectively. Thus, such change in values illustrates the prowess of pressure differentials.

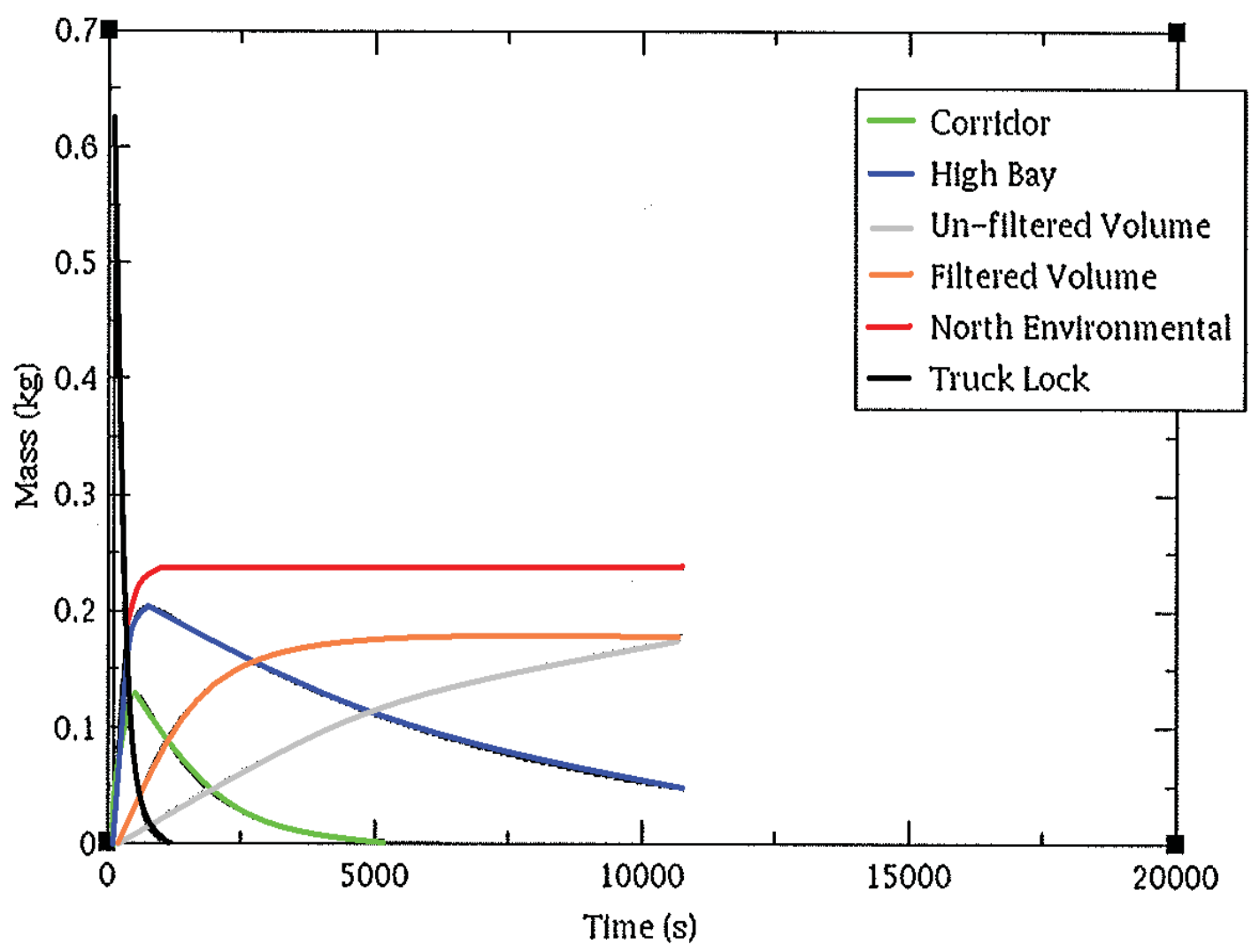

Figure 26. Control volume atmospheres given no heating, ventilation, and air conditioning air flow.

The basis for the $50 \times 50$ assumption is unknown; however, DOE G 151.1-2 refers to EPA 550-B-99-009, "Risk Management Program Guidance for Offsite Consequence Analysis," Appendix D, Technical Background, ${ }^{27}$ which describes a similar result and may provide a feasible basis for the $50 \times 50$ assumption. DOE G 151.1-2 states: "The methods described in EPA 550-B-99-009, "Risk Management Program Guidance for Offsite Consequence Analysis," Appendix D, may be used to represent the effect of building confinement." EPA 550-B-99-009, Appendix D, states: "The value of 55 percent emerged as representing the mitigation that could occur for a release scenario into a building. Data are provided on the maximum release rate in a building and the maximum release rate from a building. Making this direct comparison at the lower maximum release rate $(3.36 \mathrm{~kg} / \mathrm{s})$ gave a release rate from the building of 55 percent of the release rate into the building. Using information provided on another maximum release rate $(10.9 \mathrm{~kg} / \mathrm{min})$ and accounting for the time for the release to accumulate in the building, approximately 55 percent emerged again." This statement does not directly state that a $55 \times 55$ assumption can be applied to a release within the confines of a facility. But rather, alludes to the support of such. 
Furthermore, EPA 550-B-99-009 goes on to say: "A mitigation factor of 55 percent may be used in the event of a gaseous release which does not destroy the building into which it is released." So, this quote states that the $55 \%$ mitigation factor applies to a gaseous release. Hinds $1999^{28}$ gives that an aerosol is essentially a grouping of solid or liquid particles within a gas; however, EPA 550-B-99-009 states that the results support a regulated substance that is a gas at ambient pressure, and does not specifically describe or support an aerosol release. EPA 550-B-99-009 also states: "For the worst-case consequence analysis, you must assume that a gaseous release of the total quantity occurs in 10 minutes." This statement describes a total release of a gas; however, it does not describe the release of a solid particle suspended within the gaseous release. However, if it was assumed that a total gaseous release would include a total particle release of all particle sizes, the $0.55 \times 0.55$ results could be correlated with the experimental results shown in Figure 20. The experimental results showed that the $0.55 \times 0.55$ assumption, and thus the $0.50 \times 0.50$ assumption, were fairly accurate for a total release of all particle sizes. However, these assumptions greatly underestimated the results for the applicable release of only the respirable size range. Thus, further diminishing $0.50 \times 0.50$ assumption basis documentation, because, to account for a respirable LPF as is required for a respirable ST calculation, one must account for those particle less than or equal to $10 \mu \mathrm{m}$, not a total quantity of all particle sizes implicit in a total gaseous release.

DSA-003-HFEF states: "It is usual practice to assume an LPF of 0.5 for each enclosure that the released gas flows through." DSA-003-HFEF also describes the $50 \times 50$ assumption; however, the wording, "released gas flows through," again alludes to gas as the source of applicability for the $50 \times 50$ assumption and further tying $50 \times 50$ to the $55 \times 55$ results.

So far, observations have been made that may show some basis of the $50 \times 50$ assumption within the $55 \times 55$ percent mitigation results. These observations would decrease the ability to apply the assumption with competence. However, the fore stated observations are just that, observations, and are within a realm of uncertainty. Further review of DSA-003-HFEF shows that the $50 \times 50$ assumption is used for postulated accidents within the HFEF hot cells only. DSA-003-HFEF states: "A number of potential accidents that could affect the hot cells were identified. They cover accidents related to operations, external events, and natural phenomena." So, all previous observations aside, the $50 \times 50$ assumption is based on hot cell releases only. This observation also correlates with experimental results shown in Figure 21. When the truck lock was treated as a confined building with only one flow path into the corridor volume, it was essentially mimicking the setup of the hot cells, or a confined volume with a speculated release to the corridor volume.

\subsection{Particle Characteristics}

Each particle was classified under Class 15, concrete, which is the default class used for a solid aerosol, to account for deposition. Deposition characteristics depend on the amount of mass released into the air, so, to add further validity to the LPF, masses equivalent to MAR were used. Of the mass released, $100 \%$ was assumed aerosolized and 100\% respirable, as air fractions and respirability are accounted for in the ST equation. Typically, as the maximum diameter increases, the LPF decreases because the LPF is based on the ratio of mass released to total mass, and with larger diameter, there is a greater settling and agglomeration, thus less release. However, as was done in this study, the diameter in conjunction with the nominal density may be normalized to $10-\mu \mathrm{m}$ AED to neutralize the settling characteristics of diameter. The particle characteristics discussed below are those that are important to atmospheric transport and may be accounted for and manipulated within the MELCOR code, thus possibly playing a role in the LPF calculation. Additionally, the particle/chemical characteristics that affect particle settling and agglomeration do not play a significant role until the respirable range is exceeded, thus do not play a significant role in this study. 
Particle settling velocity may be addressed within the MELCOR code. With the input of a control function, the MELCOR code can model a bin structure that allows determination of the bin-by-bin mass for Class 15 particles within the volume of interest by time, ${ }^{20}$ thus tracking the agglomeration and settling within the volume of interest and providing the ability to distinguish the quantity of settled particles from the quantity of particles in the atmosphere. Within the bin structure are bins with a maximum particle diameter limit. As soon as the particles combine they fall out of the atmosphere and into their respective bins. This bin structure specifies the amount of automatic plating and allows a more accurate assessment of the particles in the atmosphere. Also, gravitational settling velocity depends on the density of air and the diameter of the particle, both of which are modeled in the MELCOR code and directly influence the LPF. By normalizing the particles to $10-\mu \mathrm{m}$ AED, which accounts for nominal density and diameter, the differences in settling were eliminated and a constant LPF was produced for each normalized particle.

As in atmospheric dispersion, the particle size distribution is typically represented by a lognormal distribution as described Section 1. Also, chemical reactivity can be addressed via oxidation reactions within pyrophoric fires, by the input of energies for each radionuclide. However, for the case of LPFs, radioactivity is typically neglected due to miniscule decay heat, and thus, consistent pressure gradients due to fairly large volumes and constant temperatures. The height of the different flow path layers within atmospheric transport can be addressed when designating flow path elevation (height). However, for this study, a height of one-half of the total height of the room of interest was assumed. Additionally, chemical form resistance to deposition is non-applicable. In the MELCOR code, the LPF and thus deposition is driven by flow area, bin structure, and agglomeration. Though, flow resistance of flow paths can be modeled by MELCOR code hydrodynamic packages. These effects are modeled by input of control functions that define friction coefficients. However, this approach is very laborious. ${ }^{20}$

Overall, the calculation capabilities within the MELCOR code for aerosol agglomeration and deposition processes are based on the MAEROS computer code. The MAEROS computer code is a multicomponent aerosol dynamics code that assesses the size distribution of each aerosol component as a function of time. The size distribution is described by the mass in each size bin, which may have a specific and individual chemical composition. Therefore, each bin is an aerosol group of a certain size and material type. ${ }^{20}$ Aerosols can directly deposit onto heat structures and water-pool surfaces through multiple processes such as gravitational settling as described above; diffusion to surfaces; thermophoresis, a Brownian process causing migration of particles toward lower temperatures; and diffusiophoresis, deposition induced by condensation of water vapor onto structural surfaces. Also, the surface condition can be changed, and or, deposition upon a particular surface can be disabled. Additionally, when considering water soluble aerosols, a hygroscopic effect, or solubility, where the particles can grow by absorbing water vapor from moist, unsaturated atmospheres, may be considered. ${ }^{20}$ 


\section{CONCLUSION}

This study demonstrated a process in which the MELCOR code was used to model a proposed hazard scenario within a facility of interest, and the subsequent evaluation of an LPF implicit in that scenario. The procedure accounted for a multitude of airflow pathways, both interior and exterior, through a combination of control volumes. This study was conducted to assess multiple LPFs, thus allowing a comparison of modeled LPFs to assumed LPFs. The experimental results (see Section 3) greatly diminish the validity of the $0.50 \times 0.50$ assumption by displaying a lack of conservatism implicit in the assumption. To accompany the experimental values, a literary review was completed to identify a basis of the $0.50 \times 0.50$ assumption. This review identified that the assumption can only be reasonably applied for a main cell release. Furthermore, this observation was supported by the experimental data shown in Figure 21. In addition, there appears to be evidence rooting the $0.50 \times 0.50$ assumption in the $0.55 \times 0.55$ assumption results (see Section 3 ), thus decreasing validity for the application of the assumption. Given the experimental data in conjunction with the assumption basis found in the literature review, I recommend that future application of an LPF of less than one might be applicable for confined cells; however, future analysis must be done before an LPF of less than one can be definitively applied.

Furthermore, further work into the analysis of the LPF is warranted. There will be situations where the standard value of one for an LPF is over conservative. Perhaps, a fractionated version of the LPF assumption may be developed. This version would apply standard values of fractionation, where a specific fraction of the MAR within the control volume of initiation, may be released at a specific fraction, to another control volume.

This study also included an evaluation of particle characteristics and their affect on the LPF.

\section{REFERENCES}

1. GDE-437, "Developing and Maintaining Emergency Management Hazards Surveys," Rev. 5, January 28, 2009.

2. DOE O 151.1C, "Comprehensive Emergency Management System," United States Department of Energy, November 2005.

3. DOE/ID-10471, Siaughterbeck, D. C. (1995), “Accident Assessments of Idaho National Engineering Laboratory Facilities."

4. 10 CFR 830, "Nuclear Safety Management," Subpart B, "Safety Basis Requirements," The Code of Federal Regulations, January 10, 2001.

5. DOE G 151.1-2, “Technical Planning Basis,” July 2007, United States Department of Energy.

6. Gesell T., Eisenbud M. (1997), "Environmental Radioactivity.” Academic press.

7. Polizzi et al., "Leak Path Factor Evaluation Methodology For Nonreactor Nuclear Facilities," Washington Safety Management Solutions, LLC. - Polizzi, L. M., "Leak Path Factor Evaluation: A MELCOR Application for Nonreactor Nuclear Facilities." Washington Safety Management Solutions, LLC.

8. Mueller, C. J., "American Nuclear Society Fifth Topical Meeting on Emergency Preparedness and Response, Sensitivities to Source-term Parameters of Emergency Planning Zone Boundaries for Waste Management Facilities," April 1995.

9. Siebe et al. (2007), "Ensuring Conservatism/Lessons Learned in Leak Path Factor Calculations with MELCOR,”LA-UR-07-2386.

10. ECAR-951, "Calcine Disposition Project Unmitigated Accident Dose Consequence Analysis," May 2010. 
11. DSA-003-HFEF, "HFEF Safety Analysis Report," Chapter 3, HFEF Hazards Assessment, Rev. 4, September 2008.

12. ECAR-475, "HFEF DSA Upgrade Decon Cell Fire Accident Dose Consequence Analysis," July 2009.

13. DOE-HDBK-3010-94, "Airborne Release Fractions/Rates and Respirable Fractions for Nonreactor Nuclear Facilities," United States Department of Energy, December 1994.

14. "MELCOR Computer Code Application Guidance for Leak Path Factor in Documented Safety Analysis," Final Report, United States Department of Energy Office of Environmental, Safety and Health, May 2004.

15. John Hopkins University School of Public Health.

16. Breysse, P. et al., http://ocw.jhsph.edu/courses/PrinciplesIndustrialHygiene/PDFs/Lecture4.pdf, Johns Hopkins University School of Public Health

17. "BCES: Module 3: Characteristics of Particle-Size Distribution," United States Environmental Protection Agency, January 2010.

18. Leonard, M. T., and McClure P., "Direct Calculation of Leak Path Factors For Highly Compartmentalized Buildings,” LA-UR 98-1880, June 1998.

19. Department of Energy MELCOR Leak Path Factor Guidelines.

20. R. O. Gauntt et al., "MELCOR Computer Code Manuals," Volume 1: Primer and Users' Guide, Version 1.8.6, NUREG/CR-6119, Rev. 3, SAND2005-5713, September 2005.

21. Shaffer, C., and Leonard, M., "Leak Path Factor Analysis For The Nuclear Materials Storage Facility.” LA-UR-99-2513, June 1999.

22. Schrader, B. J. (2003), "Development and validation of a dry deposition model," Idaho State University Dissertation.

23. Chamberlain, A C., and Chadwick, R. C. (1953), "Deposition of Airborne Radio-Iodine Vapor," Nucleonics 8, pp. 22-25.

24. Sehmel, G. A. and Sutter, S. L. (1974), "Particle Deposition Rates on a Water Surface as a Function of Particle Diameter and Air Velocity, J. Rechs. Atmos., III, 911-918.

25. http://dictionary.reference.com/.

26. GDE-438, "Developing and Maintaining Emergency Management Hazards Assessments, Rev. 4, September 19, 2008.

27. EPA 550-B-99-009, "Risk Management Program Guidance for Offsite Consequence Analysis," Appendix D, Technical Background, United States Environmental Protection Agency, Office of Solid Waste and Emergency Response, April 1999.

28. Hinds W. C. (1999), Aerosol Technology, J. Wiley. http://dictionary.reference.com/. 